Movement With Pedagogies in Inquiry

By

Alicja Frankowski, BA, Ryerson University, 2015

A Major Research Paper

presented to Ryerson University

In partial fulfillment of the requirements for the degree of

Master of Arts

In the program of

Early Childhood Studies

Toronto, Ontario, Canada, 2020

(C)Alicja Frankowski, 2020 


\section{AUTHOR'S DECLARATION FOR ELECTRONIC SUBMISSION OF A MRP}

I hereby declare that I am the sole author of this MRP. This is a true copy of the MRP, including any required final revisions.

I authorize Ryerson University to lend this MRP to other institutions or individuals for the purpose of scholarly research.

I further authorize Ryerson University to reproduce this MRP by photocopying or by other means, in total or in part, at the request of other institutions or individuals for the purpose of scholarly research.

I understand that my MRP may be made electronically available to the public. 


\title{
Movement With Pedagogies In Inquiry
}

(C) Alicja Frankowski, 2020

\author{
Master of Arts \\ Early Childhood Studies \\ Ryerson University
}

\begin{abstract}
The following work follows my transition from an early childhood educator co-researcher to a master's researcher in a pedagogical inquiry project in relation with movement. This MRP presents two articles that draw on a pedagogical inquiry project in Toronto, Ontario. Educators and researchers collaboratively investigated movement pedagogy through conversations and provocations in the playground. Of particular interest to this MRP is a rethinking of documentation practices, as well as discussion of what it might mean to move well together in early childhood education. The first article presents documentation as performativity as a way of rethinking boundaries between the human, material, and subject in representational practices. The second article thinks with movement practices as a moving with species of least concern through the redefining of environment as a meshwork. Overall, this work advances educator pedagogical inquiry research and provides possibilities for reimagining early childhood practices around inquiry, movement, and documentation.
\end{abstract}




\section{ACKNOWLEDGEMENTS}

I'd like to thank Dr. Nicole Land who has shown me what it might really look like to take other's ideas seriously in pedagogy and who I could not have done this MRP without. I'd also like to thank the educators at the centre I worked with who I have thought with throughout my journey as an early childhood educator and in particular throughout these last few months. I want to thank the many pedagogists and participants in the Ontario Provincial Centre of Excellence for the Early Years that I have had conversations with who furthered my thinking in opening up the possibilities of what Early Childhood Education could look like. Lastly, I'd like to thank my sister Diana and my patient partner Dominik who put up with my ramblings throughout the last two years (and before that too!). 


\section{TABLE OF CONTENTS}

AUTHORS DECLARATION

PAGE

ABSTRACT

ACKNOWLEDGEMENTS

TABLE OF CONTENTS

LIST OF TABLES

LIST OF FIGURES

LIST OF APPENDICES

INTRODUCTION

My Initial Intentions and Curiosities as a 'Moving' Educator/Researcher in Pedagogical Inquiry

Movements in Research

Situating Place and Movement as Colonial Bodies

In Thinking with Classifications, Standardizations and Boundaries

Doing Pedagogical Inquiry Research

Situating Our Pedagogical Inquiry Work

My Role as an Educator/Researcher and Researcher

Inquiry and Common Worlds Approaches

Format of this MRP

ARTICLE 1: MOVING WITH CELLU-BODY PEDAOGICAL DOCUMENTATION IN EARLY CHILDHOOD EDUCATION

Introduction

A Different Kind of Coming Together

Entangled Story One: Monstrous Material Relations

Bare-foot Knowledges

Becoming in Attention

Entangled Story Two: Documentation: The Conceptual, Material and Performative in

Relation

Moving With Documentation

Entangled Story Three: Staying with the Trouble of Cellu-body

Entangled Story Four: Performed Cellu-lines and Meshworks

Final Thoughts

ARTICLE 2: UNCOMMON RELATIONSHIPS-MOVING WITHIN A MESHWORK

Thinking with Commons and Un-commons

Onto-entanglements With-in Meshwork

Initial Pedagogical Discussions and Provocations

Mushroom Traces

To Label or Not to Label - Contemplating Communication $\quad 58$

Entrance in Symbiosis and Non-symbiosis, Commons and Un-commons 63

Moving Along the Line of Distaste-ful Relation-ship.

Final Thoughts 
Appendix A: Letter to Parents

Appendix B: Letter to Educators

Appendix C: REB Approval

References for the Introduction

References for Article 1

References for Article 2 


\section{LIST OF FIGURES}

Figure 1.1. Documenting our questions and wonderings in nonlinear collective ways on a bulletin board.

Figure 2.1. Monstrous relation.

Figure 2.2. Moving with documentation.

Figure 2.3. Staying with the trouble by weaving paper.

Figure 2.4. The path of unknowns.

Figure 2.5. The Emerald Ash Border is wanted.

Figure 3.1. No boundaries and the mushrooms we can't see.

Figure 3.2. The snail and the ch-worm. 


\section{LIST OF APPENDICES}

Appendix A: Parent/guardian Letter of Information and Informed Consent

Appendix B: Educator Letter of Information and Informed Consent

Appendix C: REB Approval 


\section{Introduction}

In this introduction, I share an explanation of my initial motivations for thinking with movement by discussing what led me to an interest in movement pedagogy. I describe my intentions to think with movement as a white settler and discuss the classification systems that I want to intervene in that are currently contextual to movement pedagogies in Ontario. I then outline the methods and practices of the early childhood education pedagogical inquiry research that inform my project, the ways in which the inquiry was situated and how we (me, the educators, and Dr. Nicole Land) established and initiated our research, the transition between my work as an early childhood educator to a masters researcher, and a description of common worlds research in inquiry as a methodology to think with. I also describe the format of this Major Research Project (MRP) which I have chosen to write as two articles because of the multifaceted nature of pedagogical inquiry work. I then outline the intentions of each article, showing how each fits into my larger project. I conclude by sharing some propositions and questions with movement that I want to think with/in my work.

\section{My Initial Intentions and Curiosities as a 'Moving' Educator/Researcher in Pedagogical Inquiry}

\section{Movements into Research}

I began this research as an early childhood educator in an early years setting with my own interests in outdoor movements and what it means to approach movement pedagogy in early childhood education. I was also interested in thinking with movement with more than human 
worlds1. My own passion for hiking and outdoor activity in rocky, watery, forest-covered messy environments led me to question the hyper-categorized practices that currently reside in early childhood education, which monitor how we (educators, children, the nearby community) move and regulates what is expected of a movement environment. I thought about this within the context of biopower2 and play rhetoric and how categorizing children's movement has been taken up as a component of neoliberal ethics, of progress and competition, body identity, and a value in what movement is good for, rather than considering how we might be in an embodied movement in sense with another (Allen-Collinson \& Owton, 2015; Culp, 2017; Hackett, 2016; Sutton-Smith, 1997; Woodyer, 2008). As an early childhood educator, in my care for how we move with more than human worlds, I noticed the lack of awareness in early learning discourses in how daily rituals were implicated in the destruction of species and created limited possibilities of moving with these species; I have encountered and engaged with these destructions and limits personally in my own practices. Throughout the pedagogical inquiry work that informs this research (which I discuss further in the following sections) as well as other projects I was engaged in (for example, the Ontario Provincial Centre of Excellence for the Early Years and Child Care), my interests in thinking differently with movement were nourished by a wide range of scholars, activists, feminists, and post-structural philosophers that grounded me in what it means to move as a settler amid the consumptive and extractive logics of ongoing settler colonialism. Concerned with ontological structures around humanism and what it means to be a

1 When I speak to the term more than human worlds I speak to knowledges and existences that are not subject to the sovereign human body. I use the term more than to disrupt the binary of human and nonhuman and to re-imagine dwelling that is not solely marked by human-centrism.

2 When using the term biopower I am borrowing the use of Foucault (1976) in the philosophical work of sport science theorists (Culp, 2017) in exploring the way power over bodies is exercised. I discuss this concept in early childhood education because I am concerned about the ways in which the field has taken up control over bodies and material worlds in the name of neoliberalism, ownership and progress. 
human (St. Pierre, 2000), I wondered about my questions with movement next to a general question proposed by Cristina Delgado Vintimilla (2018) about pedagogy: What does it mean to live/move well together in early childhood education? With this question, I thought with early childhood reconceptualists about who I was allowed to be as an early childhood educator in this particular place, given the inherited histories that are saturated in neoliberal knowledges of a productive output that limits what it means to live with/in diversity, and what it meant to work in question (Moss, 2010, 2016).

\section{Situating Place and Movement as Colonial Bodies}

The research takes place at an early childhood education program in Toronto, Ontario. This place carries with it histories that are important in approaching the ethics and politics of an urban area, surrounded by students, nonstudents, condoms, needles, garbage, and precarity. The university that surrounds the school is named after Egerton Ryerson who introduced the residential school system for Indigenous peoples in Canada and created a direct boundary for what it meant to participate in education as white settler children vs. Indigenous children. In religious partnership with various denominations and in contrast to his enforcement of church and state divisions for white settler children, Ryerson enforced residential schools as a response to his belief that Indigenous children should be civilized and mainstreamed, resulting in violence and multi-generational trauma for Indigenous families (Aboriginal Educational Council, 2010). It is on this treaty land, named after this violent figure, that $\mathrm{I}$ - a settler to this place - was an educator engaging in innovative early childhood education. To note, Ryerson University is situated on treaty land which currently has the following land acknowledgement: 
Toronto is in the 'Dish With One Spoon Territory'. The Dish With One Spoon is a treaty between the Anishinaabe, Mississaugas and Haudenosaunee that bound them to share the territory and protect the land. Subsequent Indigenous Nations and peoples, Europeans and all newcomers have been invited into this treaty in the spirit of peace, friendship and respect. (Aboriginal Education Council, 2019, para. 1)

I speak with these colonial histories that I inherit and my desire to think with post-human, feminist scholars to disrupt the taken-for-granted sovereign, isolated humanist understandings of bodies and subjectivities that are focused on neoliberal logics of progress and economic growth, rather than the ethical implications of what we do in the mundane. At the same time, I am equally in distrust of my own actions, as a privileged white settler, as I learn from scholars such as Eve Tuck and Wayne Yang (2012) and Peter Cole (2012), who point to the fallacy (and violence) of decolonizing as metaphorizing, or moving to innocence, and the importance of resisting a translation of Indigenous culture (I see these types of translations in our redemptive quick moves to incorporate Indigenous knowledge and language in early learning). I take seriously Donna Haraway's (2016) suggestion of staying with the trouble of what it means to live on a planet in environmental turmoil, and in the case of my research, the colonial extractive logics that have led to classifications and boundaried divides with others, and to the illegitimization of other bodies and material. It was these suggestions that provoked me to enter this pedagogical inquiry project, hesitantly as an ethical practice, while attempting to open up or permeate these boundaries toward a more livable future. As a personal and ethical pedagogical commitment, it is my hope to resist these quick fix solutions while continuing to attend to more than human worlds as a politics in place. When I use the word colonial in my work, I am speaking to some disruptions I can make within early childhood education practice to contest 
neoliberal and ownership narratives. My work does not speak to legitimizing anything, nor does

it claim to decolonize. Rather, I attempt to speak to staying with the trouble imperfectly, knowing that white settler solutions to what knowledge means are consequential and powerful. Instead of proposing new best practices, I want to keep asking: how does legitimization happen in early childhood education and what does it do to legitimize in our work with children?

\section{In Thinking With Classifications, Standardizations and Boundaries}

The neoliberal shift in early childhood education has framed educators as technicians who follow prescribed categorical documents based on free market principles of competition and ownership. This shift has led to diverse and biodiverse knowledges being overlooked in order to attend to the bottom line in service-providing childcare (Moss, 2010). As an early childhood educator, I often responded frustratingly to neoliberal and developmental policy documents and their attached quota systems and quality narratives that lead to categorical closed thinking of what it means to be a good early childhood educator. In light of these frustrations, I have been interested in unsettling the prescribed way we move in early childhood education and the ways in which I notice movement in these settings. Underpinning these categorizations that are described in developmental policy documents and that structure our moving, are boundaries that are consequential to what constitutes one thing or another, nature or culture, the legitimate and illegitimate body, human or nonhuman, good educator or bad educator, and good documentation or bad documentation. The list of binaries is endless, while the events I have chosen to write about and respond to in this MRP speak to how these binaries are entangled and consequential.

I think with movement pedagogy. In response to the field's tendency to exercise knowledge and represent one truth in how we think about movement (for example: developmental motor skills), I think of performativity as material, physical, corporeal 
movements entangled with the ways we exercise power and knowledge formation (Foucault, 1980, pp. 58-59 as cited in Larsson \& Quenderstedt, 2012), while making perceivable gendered and racialized body materializations (Butler, 1990, p. 136 as cited in Larsson \& Quenderstedt, 2012), and attending also to nonhuman matter materializations (Barad, 2007 in Larsson \& Quenderstedt, 2012). I think with these material performativities as intra-active and agentic, picking up how Karen Barad (2007) views the social and the material as entangled performativity rather than representational practice, and calls us to think with diffraction rather than reflection3. In this way, Barad melds together an "ethico-onto-epistem-ology" (p. 90) in speaking against the Cartesian mind/body dualisms that have served a privileged Euro-Western aristocracy, where these dualisms assume a knowledge of the objective Other and that humans have the logical sense and cognitive superiority to solve the problem of the other. In this work, I explore how Euro-Western knowledges have contributed to ownership and consumption of nonhuman bodies and materials. I think with performativity and diffraction as starting points in playing with how I might be able to relate or form relationship with species and humans in early childhood, while understanding that no human/nonhuman is fully knowable. When I engage with curriculum documents, and think how they form moving bodies, as well as in the material inheritances of documentation and its purpose in early childhood education, I also think with how they have sought to create a single white settler story of what movement (and also documentation of movement) means in early childhood education.

3 Rather than thinking of reflection in early childhood education where our observations or perceptions define the Other, I use Karen Barad's term diffraction to speak to the differences we make and bring forward while being entangled with others. I think about diffraction to speak to our practices of representation in early childhood education that homogenize what it means to experience movement, early childhood and engagements with more than human worlds. 
As a refusal to engage in research that centers Euro-Western conceptions of a representational body, I am interested in research that disrupts the unitary sovereign individual body and is able to freely move and think with more than human worlds unequivocally. I recognize storying as a response to classifications with Tim Ingold (2011) as he discusses that "stories always, and inevitably, connect what classifications divide” (p. 160). Similarly, I seek to engage with story as non-innocent while attempting to practice what Donna Haraway (2016) describes as multi-species storytelling or "stories in which multispecies players, who are enmeshed in partial and flawed translations across difference, redo ways of living and dying, attuned to still possible finite flourishing, still possible recuperation" (p. 10). My work also moves with Anna Tsing (2015) who discusses troubled storytelling in precarity in the failure of the modern progress story in hyper-capitalism. I have been deeply moved by Donna Haraway's (2016) description of storytelling in trouble as she states:

It matters what matters we use to think other matters with; it matters what stories we tell to tell other stories with; it matters what knots knot knots, what thoughts think thoughts, what descriptions describe descriptions, what ties tie ties. It matters what stories make worlds, what worlds make stories. (p. 12)

I first heard this poetic description of storytelling with a group of pedagogists during an online chat. Throughout this research, I think with stories that tell stories to unravel and complexify knots and participate in a worlding through an imperfect type of storytelling that attempts to disrupt the unitary sovereign colonial subject and the representational, objective practices of recollection that are enabled by conceptions of the individualist, bounded human.

\section{Doing Pedagogical Inquiry Research}




\section{Situating our Pedagogical Inquiry Work}

The following work walks alongside my transition from an educator/researcher to researcher as part of a larger project initiated by Dr. Nicole Land. To begin our pedagogical inquiry research, our group - early childhood educators Andrea Thomas, Maria Wysocki, and Selena Ha4, and researchers Dr. Nicole Land, and I - met weekly to discuss how moving happened in one classroom and yard for preschool-aged children. This work is ongoing, but my research shares some of our thinking from May, June, July, and August 2019. Our work has been approved by the Research Ethics Board at Ryerson University (please see Appendix A for Parent/Guardian, Appendix B for Educator, Letters of Information and Consent Forms and Appendix C for REB Approval). Each week, we discussed questions, concerns, and wonderings about how we move with children and more-than-human others in the playground. Beginning from the question "why care about moving in early childhood education?", our central question for coming together became "how do we move well within the playground?". As we tried to activate this question, we grappled with many additional ethical and political questions including: What would it mean to document this sort of experience beyond stories of representation? How might bare-foot5 pedagogies of/with moving shape how we build curriculum with moving with children, to think moving in multiple, less familiar ways? What would we be, how could we be, if we stopped allowing borders to be the way we organize ourselves? Later each week, we would engage in provocations with the children that served to activate some of these questions in our outside space. We documented each provocation using photos taken with on-site cellphones and cameras (which we stored in a Google Drive), printing

4 The educators I have worked with have all given permission and consent to use their names in this paper.

5 In using the term barefoot pedagogies, we were speaking to events and provocations around moving bare-feet in the playground and the kinds of conversations that may open up when we engage with material without our shoes. 
out photos, playing with note taking on the photos, and by creating a multi-layered and messy bulletin board to connect ideas and intentions in new and non-linear ways (Figure 1.1). Our provocations predominately unfolded within the vicinity of the sandbox. Inside of the sandbox, there lay sand and decaying logs, while slightly out of the way of the sand box was a wire fence where we could look out onto the campus. Some of the provocations that we invited the children to think with included for example, the creation of boundaries with newly cut down trees and paper to explore boundary making, a purposeful omitting of toys in the playground in response to a question of what it means to relate with more than human species in non-consumptive ways, and the addition of insect photos in the playground. Each provocation was followed by email chains where we continued to discuss how thinking with the children amplifies our own thinking and raises unfamiliar questions. The emails were revised into to an online blog that reflected our shared thinking (Moving Pedagogies Blog, 2019).

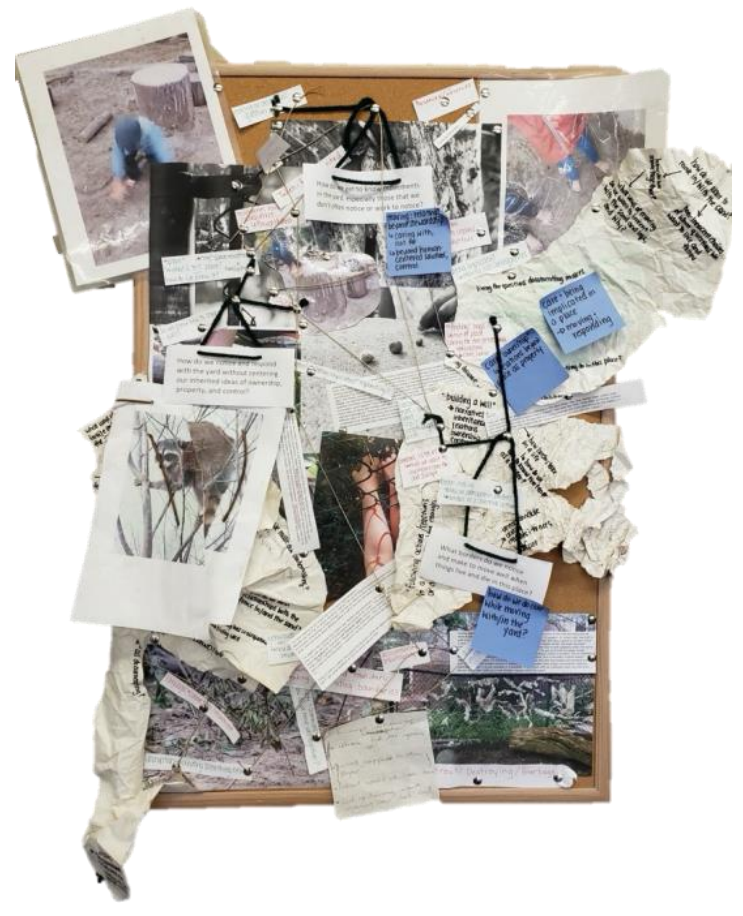

Figure 1.1. Documenting our questions and wonderings in nonlinear collective ways on a bulletin board. 


\section{My Role as an Educator-Researcher and Researcher}

This MRP follows me through the roles of a contract educator co-researcher to a researcher in our pedagogical inquiry work. This journey has been rocky at best, as I negotiated what it means to fluidly move from place to place - from the responsibilities tied to an educator to the responsibilities tied to a visiting researcher - engaging with grounds I once saw as comfortable, homey, and familiar. I am reminded of Anna Tsing's (2015) description of precarity as a condition of being "vulnerable to others" (p. 20). Tsing describes precarity as the "condition of our time" (p. 20) shared with multi-species others. Flawed and broken dreams of modernization and progress, and its effects on earth call us to let go of control - and as Tsing (2015) says, even of ourselves (or in my case of an educator in charge of managing a space). In particular, Tsing asserts that a need for precarity is ripe, acknowledging that we cannot rely on the status quo. I believe this is what precarity has opened up in my engagement with non-human species with the children who I thought with in this research. Some of what I have written speaks to the attention needed to engage politically when moving with other species, ideas and documentations, the tensions this had with my body (which was initially programed to scan and supervise), and the way this work unapologetically asked me to stay with trouble. Initially, it was my goal to engage myself as an educator in rigorous questioning of my role in the day to day, and to hold an empowered view of the educator as one who is able to notice the tensions in my practice. However, precarity - both in my employment as an insecure contract employee and in tending to the lives and deaths of everyday worlds with the children - has given me a different and unexpected tension to think with, and has called me to notice what often is ignored; what

Paulina Rautio (2017) describes as "listening to what the world speaks to us" as a "not-self" (p. 97). I think back to precarity and what it means to be vulnerable with species of least concern. 
Tsing (2015) explains that the vulnerability that resides in precarity is an indication that we (as multispecies and matters) are in need of help or the service of the other, whether we are aware of it or not. As quick and technical problem solving becomes the status-quo of hyper-capitalist and neoliberal solution-making in early childhood education, I think that precarity enables me to think in a different kind of collaboration, one that is able to work collectively while not in complete agreement (and there is something very beautiful about this commons in (un)commons6 that I believe is needed to disrupt the unitary solution-finding subject). I want to make clear that this is not a moralizing statement of whether precarity is good or bad. Nor do I suggest, that I stand behind precarity, as I am ethically entangled in a responsibility to adhere to particular conditions for educators in early childhood education in Ontario. However, in unstable times, thinking with precarity opens up other possibilities for responding to contemporary worlds.

\section{Inquiry and Common Worlds Approaches}

Inspired by an approach that is experimentational rather than representational, I work with ideas about research that work to not reproduce the enlightenment histories of research (Hodgins, 2019). I am inspired by the common worlds research which approaches work interdisciplinarily and emergently and "focuses upon the ways in which our past, present and future lives are entangled with those of other beings, non- living entities, technologies, elements, discourses, forces [and] landforms" (Common Worlds Research Collective, 2019, para. 1). It is with common worlds research that I seek to blur "boundaries between methods, analysis, and so

6 I am paying attention to commons and uncommons to speak to the commonalities we share when facing an Anthropocene, while following Blaser and Cadena's $(2017,2018)$ work in thinking about goal-oriented action without a complete common understanding of each other's desires or needs. I think about this in both our understandings of what it means to move with others and also with what it means to ask pedagogical questions with one another. 
what?" (Hodgins, 2019, p. 11), and acknowledge that early childhood practices are deeply

entangled in theory. Common worlds research speaks to accountability and response-ability to

traditional Euro-Western and neoliberal research methods that describe a singular way to be in

place (Hodgins, 2019). I am drawn to a common worlds approach because of its dedicated work

in early learning spaces, and its constant emergence and move away from traditional research

approaches of utilization and application. Of particular interest to me in my work is the

disruption of romanticized notions of relationship and what it means to move with another in

inquiry. I think with the way goodies and baddiess have been distributed amid the nature/culture

binary and stewardship narratives of who protects and who destroys nature, and the borders and

boundaries that are thought up to maintain these narratives (Taylor, 2017). In framing bodies in

our pedagogical inquiry work as not-selves 9 , I participated in a different kind of inquiry written

by a multitude of scholars that move beyond innovative qualitative inquiries into feminist post-

qualitative research stories. It is with this that I think with ethico-onto-epistem-ology 10 as the

assertion that ethics, ontologies and epistemes are inseparable in diffractive ways of knowing

(Barad, 2007) that disrupt binary logics and rethink the fluidities in what it means to be

habituated in nature. I do this while acknowledging that this type of rethinking of a storying

7 I use the term response-ability originally described by Donna Haraway (2016) to move away from responsibilities as expectations that are moralized or expected and instead approach our responses to current destructions of our time as desires that are taken up collectively while participating in worlds in making rather than worlds that are defined. ${ }_{8}$ Goodies and baddies are outlined by Africa Taylor (2017) to emphasize the repercussions of the border making present in romanticized nature narratives that isolate anyone who is in the way of this romanticized nature as a body that should be villainized.

9 I use the term not-self, inspired by Paulina Rautio (2017) to describe a shift to move away from the human as the primary concern in early childhood that in turn creates possibilities for exploring what it means to be in relation with another.

10 In using the term ethico-onto-epistem-ology I am viewing what is traditionally termed as practice as inseparable from the ethics, ontologies and epistemes present in early childhood. Ethico-onto-epistem-ologies are described by Karen Barad as a component of a diffractive approach to research rather than a reflective approach to research that constitutes the image one holds as a complete representation of what's there. This is a combination of a material knowing (onto-epistem-ology) and its entanglement with ethics. Karen Barad approaches this with an understanding of quantum physics, and its assertion that nothing can be fully represented rather is influenced by the observer (Barad, 2007). 
approach of knowing land is not a new one, but one held by local Indigenous populations. I want to sit with what it means to unsettle the academy and think with histories that already refused to “subscribe to Euro-Western epistemic systems" (Watts, 2013, p. 31 in Hodgins, 2019).

I am interested in the moving body as not representational but moving with species of least concern (Lorimer, 2014 as cited in Rautio, 2017). As touched on above, I am interested in the boundaries that are created between goodies and baddies in outdoor spaces as status-quo stewardship narratives follow what Taylor (2017) discusses as humanist Euro-Western logics that follow a Rousseaunean type of innocent child narrative, where the child protects the good nature from the baddies. I think with these goodies and baddies as I am interested how our movements through space with children engage in these taken-for-granted binary and protectionover, solution-oriented kinds of logics. I take seriously the way mainstream wilderness nature claims have participated in a direct erasure of Indigenous knowledges of land in education (Tuck, McKenzie, and McCoy 2014 as cited in Taylor, 2017). As a result, I think of inquiry in movement as a refusal of romanticized humanist child-centered practices and instead think of inquiry as a practice to "consider seriously what takes place in practices that children usually find inherently rewarding and spend considerable time engaging in" (Rautio, 2013, p. 395). I have chosen and learned to engage in more of a collaborative inquiry with children as habituated with the rats, worms, rocks, soil, sand and wood in our playground while acknowledging that we are entangled in relation with these non-human species and materials. I think with movement as a slow attention to notice, and question what noticing means in relation-ship (Rautio, 2017), and a re-invention of what it means to inquire with children (Clark, Pacini-Ketchabaw \& Hodgins, 2014; Land \& Danis, 2016; Nxumalo, Vintimilla, \& Nelson, 2018; Pacini-Ketchabaw, Kummen \& Thompson 2010). I think simultaneously with uncommons as Blaser and Cadena $(2017,2018)$ 
describe, and with Isabelle Stengers (2005), to think with uncommons as a coming together and transformation without equivocal sameness or understanding to what this reinvention might look like (Stengers, 2005, p. 183-96 in Blaser \& Cadena, 2018, p. 18). This opens for me a way of thinking moving where I can enter questions, provocations and wonderings with children and other educators with ethical commitments that focus on more than human relation, while understanding that my interpretations of these commitments will never be fully in agreement with others.

\section{Format of this MRP}

I have chosen to write my MRP as two articles that I intend to submit for peer-review. I wanted to create two articles as a response to the nature of inquiry and its multi-directional nature that takes one to many places rather than through linear ways of researching. As a result, I have chosen to spend time with two overarching questions or wonderings that emerged for me in this large entangled web. Because I am writing these articles while intending for them to stand independently as eventual publications, there are some slight similarities as I talk about methodology and theory in each article. The first article considers pedagogical documentation practices. It draws on three events from our inquiry work that provoked me to think with the concept of cellulose as a cellu-body11. In this article, I offer a proposition to rethink documentation by considering who gets to document (in considering humanist logics), and what constitutes proper documentation. I work to rethink documentation as performative and with response-ability to cellulose as a moving with cellulose. The second article foregrounds moving with more-than-human others in the playground. I think with moving in a meshwork to explore 
moving, communication, and relationship with species of least concern such as mushrooms, slugs and worms in the playground. I propose that the concepts presented in these articles have the potential to consider movement in outdoor spaces and lands as an ethical question and with a concern for not-selves. I hope that these articles offer forward a provocation for early childhood educators and those interested in pedagogical work to rethink status quo ways of producing and replicating early childhood practices and to engage with moving contextually, ethically, and pedagogically. 


\title{
Article One: Moving with Cellu-body Pedagogical Documentation in Early Childhood Education
}

\begin{abstract}
Drawing on an inquiry-based pedagogical project in an early learning program in Toronto, Canada, this article questions current documentation practices in early childhood education and their relations with materiality. Through storytelling, this paper discusses the work of an educator/researcher in thinking with documentation and boundary formation and deconstruction while moving in more than human worlds. It draws on four examples or entangled stories, thinking with Karen Barad's (2007) notion of ethico-onto-epistemology (an assertion that ontologies epistemes and ethics are inseparable) and posthumanist performativity to explore monstrous movements, moving documentation, staying with the trouble of paper destruction, and doing documentation with more than human others.
\end{abstract}

Keywords: early childhood education documentation practices, performativity, monstrous relations 


\section{Introduction}

This work draws on an ongoing pedagogical inquiry research project that situates curriculum as lived, ethically shaped, and political. Our research responds to current neoliberal child-centred and modernist romanticized notions of emergence and works to re-invent what it might mean to inquire with children (Clark, Pacini-Ketchabaw \& Hodgins, 2014; Land \& Denis, 2016; Nxumalo, Vintimilla, \& Nelson, 2018; Pacini-Ketchabaw, Kummen, \& Thompson, 2010). Accordingly, in our research we carefully think with the question, "Why do we care about movement in early childhood education?" collectively with educator-bodies, child-bodies and cellu-bodies 12. In this article, I draw on work created in a collective response to particular conditions of a downtown Toronto early years setting that is situated in the Dish with One Spoon territory, marked by a treaty between Anishinaabe, Mississaugas and Haudenosaunee that bind them to share the territory and protect the land (Aboriginal Education Council, 2019). This pedagogical inquiry work is a collaboration between Dr. Nicole Land, the educators in the centre, and the educators and partners in the room where I was an educator (Andrea Thomas, Maria Wysocki, and Selena Ha)13, along with many engagements and conversations I have had with children, family members, pedagogists, and more than human relations. It also follows my own path and transition from an educator in a classroom to a researcher.

Throughout this article, I follow a storytelling that is concerned with the ways in which we respond to the destructive humanist, colonial, and consumptive logics that contribute to our carbon obsessed anthropocentric time (Taylor, 2011, 2017; Taylor \& Pacini-Ketchabaw, 2017).

12 Cellu-body: I am speaking to a particular attention to cellulose and its relation with human (and other bodies). In this way I am thinking with how cellu- and body are in movement together, inseparable. Both structured and unstructured in form.

13 The educators I have worked with have all given permission and consent to use their names in this paper. 
My engagement in storytelling is inspired by common worlds scholars who think storying as form of "resisting the force field of child-centeredness" (Pacini-Ketchabaw, Taylor, \& Blaise, 2016, p. 150) by attending to how "we (children, teachers, educators and researchers) cohabit with multitudes of species" (p. 150). Following common worlds scholars, this article strives to do the challenging work, and sits in the difficulty, of moving beyond human-centric research practices with a kind of multi-species ethnography, while acknowledging "potential limits that come with human perception" (Pacini-Ketchabaw, Taylor, \& Blaise, 2016, p. 2). I take seriously Donna Haraway's (2016) suggestion that "storying cannot any longer be put into the box of human exceptionalism" (p. 39). Inspired by this proposition, the story that I tell moves along various concerns with representational documentation practices that aim to re-present an authentic, individualized, humanist moving child-body in early childhood education. In early childhood education, documentation refers to a practice of recording through pictures and writing what children have done and explored, and often takes the form of learning stories and other stories hung around the classroom for families and children to revisit. I pay attention, instead, to how cellulose and body (what I will build toward knowing as a cellu-body) move and participate in documentation practices. I think with posthumanist performativity, which Karen Barad (2007) outlines as "the givenness of the differential categories of human and nonhuman, examining the practices through which these differential boundaries are stabilized and destabilized" (p. 66). This means that I attune to boundary forming in documentation processes in for example, the materials we use and the perceived ownership of documentation (as predominately human-centered and as human property).

Entangled with my goal to disrupt representational documentation practices (Blaise, Hamm, \& Iorio, 2017), I work in this article to resist the strict neoliberal inheritances of what an 
educator, pedagogical participant, child, tree, and paper can be. As a situated educator and researcher, I respond throughout this article to neoliberal mechanisms that perpetuate the universalization of education, pedagogy, and scholarship while damaging and segregating diverse and biodiverse knowledges (Moss, 2010) by thinking otherwise with documentation. As I begin this work, I meddle with a dance between a collective inquiry and a set of wonderings about the possibilities of what documentation might be, and what can emerge if we destabilize documentation possibilities in inquiry. Then, I tell four entangled stories, spending time with these stories to build concepts and questions that I want to put into conversation with a different way of doing pedagogical documentation. I begin by thinking with a moment from pedagogical inquiry work where children were engaged in monstrous 14 relations (Colebrook, 2014) with logs (or cellu-matter). Then I discuss this type of monstrosity in the form of crossing the boundaries of the unitary sovereign subject with an example from a bare-feet jumping provocation. Following this, I discuss a provocation of messy movements with what is deemed unclean documentation. In my fourth story, I ponder documentation formed by the non-human. Then, I conclude by discussing what thinking documentation in movement and performativity has opened up and discuss possible questions for continuing to think with documentation as a performative cellu-body.

\section{A Different Kind of Coming Together}

As I discuss our initial concerns and reasons to come together in the pedagogical inquiry work that informs this article, I am reminded of a description by Mario Blaser and Marisol De La Cadena $(2017,2018)$ regarding what coming together can mean within the context of the

14 In using the term monstrosity as inspired by Colebrook's (2014) metaphor of a certain Frankenstein-ian nonhuman or non-ordinary movement. 
Anthropocene. In response to the extractive solution-oriented failures of human essentialism and the "paths of salvation" (p. 3) that currently reside in environmentalist discourse, Blaser and Cadena discuss an immediate need to bring together various interest groups by drawing on what Isabelle Stengers (2011) calls "interests in common" (p. 3). These interests are not necessarily homogenous. Rather Blaser and Cadena (2018) discuss them as "heterogeneous worldings coming together as a political ecology of practices, negotiating their difficult being together in heterogeneity" (p. 4). Resultingly, Blaser and Cadena call this type of work uncommons. As I outlined earlier, I am inspired by a common worlds approach and this conception of the uncommons is interestingly juxtaposed with a common worlds pedagogy, which seeks to create a collective worlding in order to attend to nonhuman worlds and relations (Taylor, 2017). In this space, and in consideration of this common/uncommon tension or binary, I consider the beginning point of our (me, other researchers, educators, children, documentation, trees, paper) alliance as a delicate and simultaneously tense entrance. This means that we attended this inquiry with different knowledges and intentions, and with a potential to transform collectively but unequivocally in the name of noticing and moving with more than human worlds.

To begin our work together, educators and researchers discussed our concerns about current conditions of movement discourse in early childhood education. These conversations were meddled with my own concerns (and of those I read and thought with) regarding the particular representative, innocent, redemptive and consumptive nature (Taylor, 2011) in which early childhood education has been taken up in Ontario, especially in the way we choose to represent a particular view of the human and more-than-human lively others. Our work involved weekly meetings where we discussed movement, a weekly inquiry time where we offered various movement provocations to think through with the children in response to these 
discussions, emails where we thought together about the happenings in this place and their relevance to greater discursive knowledges, and an experimentation with messy documentation practices that was entangled with earlier events. Our provocations and inquiry work were predominately in the outdoor playground. The playground occupied the grounds of an institution named after Egerton Ryerson, the primary engineer of the residential school system in Canada (Aboriginal Education Council, 2010). The playground included small settler bodies15, large settler bodies, fences that divide the inside and the outside child space, and manufactured materials including plastic and natural toys serving the purposes of play. Beyond the fences lay needles, condoms, and traces of cigarette waste, as well as bodies in varying degrees of distress that alert and instil fear and caution in educators. Within the fences of the playground, we predominately spent a lot of time with the sand box, thinking with the materials and lives that inhabit the sandbox.

As we sat weekly together, we began with a situated response to noticing monstrosity/intensity (Colebrook, 2014) and bound-ary/border making in the playground. This led to asking a question aligned with Cristina Vintimilla's (2018) question "What does it mean to live well together in pedagogical contexts?" (p. 23). We wondered: "How do we movel live well together (with each other, the sand, and its "inhabitants") in the sand box?"

During these initial conversations, the space was undergoing a campus makeover. A pile of logs had been dropped off in the sand box, that we understood were cut down trees from around campus. The logs immediately became sites for monstrous (Lenz Taguchi, Palmer \& Gustafsson, 2016) jumping and colliding. Bodies climbed, slipped, and jumped off the sandy

15 To our knowledge all the children involved in the research did not identify as Indigenous and were settlers to this place. 
logs into the sand and one another. As the classroom and outside classroom (children, educators, families, scholars, community participants) began to have overlapping group conversations about the trees, we noticed a type of melancholic attendance to the logs through our conversations: "the trees give us shade" and "we don't want the trees to be cut down". We thought about the ways in which the logs appeared in the playground, how they came with histories, and how melancholy was insufficient to these stories. We concurrently participated in boundary negotiation with what, in this particular context, were radical diversions to the norm of the early learning centre. For example, we provoked a shoes-off jumping experiment to getting to know the sand box. As the educators encouraged and took their own shoes off, the children hesitantly and then wholeheartedly joined. It was at this point shoes off took on a different life where we noticed footprints, coldness, and wetness in sand-foot-log relations. We discussed these types of rule breakings or boundary crossings by carefully considering what I interpreted as a Foucauldian attendance to biopower16 and its implications (Barad, 2007; Culp, 2017). For example, we thought with the violent ways boundaries/borders are created and enforced in various contexts (including movement discourses in early childhood) through human sovereignty, individualism, ownership, and quota systems that classify, standardize, and produce illegitimate movements and bodies, and in turn privilege white, masculine and able-bodied humans (Azzarito, 2009; Culp, 2017; Markula \& Pringle, 2006). We thought of rulemaking on macroscales and debated what border-making does in light of current events that were taking place south of the border in our current geopolitical climate.

16 When using the term biopower I am discussing the way power over bodies is exercised. This is important if we are to approach movement pedagogies ethically. In particular, I thought of biopower as boundary/border making in early childhood. 
These, what I would call, violent narratives of inherited borders and categories were seen not only in the politics of rule enforcement on humans, but also (and possibly in tension) in the very politic of the borders (and materials) themselves. Materials such as the trees and logs in this playground space were often used to include and exclude other beings, creating and limiting possibilities for various entanglements. Cellu-borders (trees, bodies) were made to create shelters with the children, followed by the phrase "you can't come in." Children used cellu-matter to isolate insect movements in order to trap them. We began to discuss our ethical engagements with matter, as emphasized by feminist science studies scholar Karen Barad (2007). Barad introduces an ethics of matter-ing that is entangled with ontology and epistemology, an ethicoonto-epistem-ology (p. 90). In this case jumping, an action composed of infinite participants including muscle, keratin, sand, cut wood (cellulose, glucose), boundary-making and the narratives and documents we chose to frame borders with, the materiality we leave out, and the way we frame engagement with material all have political consequences for how we could discuss and attend to movement discourse as a practice in relation. By thinking relationally of our bodies as material entangled with other material, we wondered how we might begin to think resistances to essentialist sovereign body stories and the separations that exist in status-quo documentation practice.

\section{Entangled Story One: Monstrous Material Relations}

We began to weave the politics of materials together with boundaries in the playground. We were provoked by Nicole to frame monstrous movements through Claire Colebrook's (2014) notion of queer vitalism and Lenz Taguchi, Palmer and Gustafsson's (2016) adoption of queer vitalism as a way to explore a "war on norms" (p. 706) in dance practices with children. By using 
queer vitalism as a means of gazing beyond the individual human to understand dancing bodies as an assemblage that is part of the other, both of these texts described monstrosity through a Deleuzian notion of individuation as a state of becoming-with that refuses centering normative, bounded subjects (separated children, logs, educators) as primary referents of concern (Colebrook, 2014; Deleuze 1994, in Taguchi, Palmer \& Gustafsson, 2016). This, for me, was an interesting way of framing movement that alerted any moving body to another, because it spoke to both my dedication to think about moving as non-normative, and to think about moving together with each other and the more than human as collective or entangled. It is with beingwith that I am creating and using the phrase cellu-body, as a practice to attend to boundarybreaking in children-paper-tree relations. A monstrous children-paper-tree relation is entangled with a messy, non-uniform engagement with knowing, and a refusal of our inherited obsession in early childhood education with centering the proper individualized subject.

While the emphasis to move away from the individualized subject is not a new one in posthuman scholarship (e.g. Barad, 2007), my thinking moved with Tim Ingold's (2011) discussion of the individualized body in relation to cognitivist mind/human-centred thinking that is rooted in modernist Eurocentric knowledge of Cartesian mind/body duality. Euro-Western, Cartesian ways of thinking lend superiority and authority to intellectualized ways of knowing. Euro-Western engagements with the world and movement are predominately shaped in a reflective or representational sense, often through cognitive configurations that Ingold argues, stem from propositions regarding a mind above ground superiority - or, the contention that we as humans (especially those with privilege) have the cognitive capability to reach an ideal solution based on the mind's perceived efficacy (Ingold, 2011). This can be seen, for example, in a logic of the critical rationale or redemptive justifications in lingering stories around the playground. 
We considered how these logics were reproduced though these familiar narratives that we encountered in the playground. For example, when we take for granted that the trees had to be cut down because they were at risk of being infested by invasive species or when we speak and describe the cut trees and how we wished we could save them, we have acknowledged our feelings (and therefore have the ability to redeem ourselves of liability); or, if we document, and print out the children's engagements, we can show their care and stewardship for the logs. These taken-for-granted rationalist and redemptive playground stories rely on a logic that separates the body from the material in the name of privileging the rational, autonomous human subject over a bodied, messy material world. To think with monstrous movements instead opens toward cultivating an open-ness to other possibilities in thinking beyond self-interested, individualized, and skill-based knowledge while opening "what a body might be and become productive of" collectively (Taguchi, Palmer, \& Gustafsson, 2016, p. 710). 

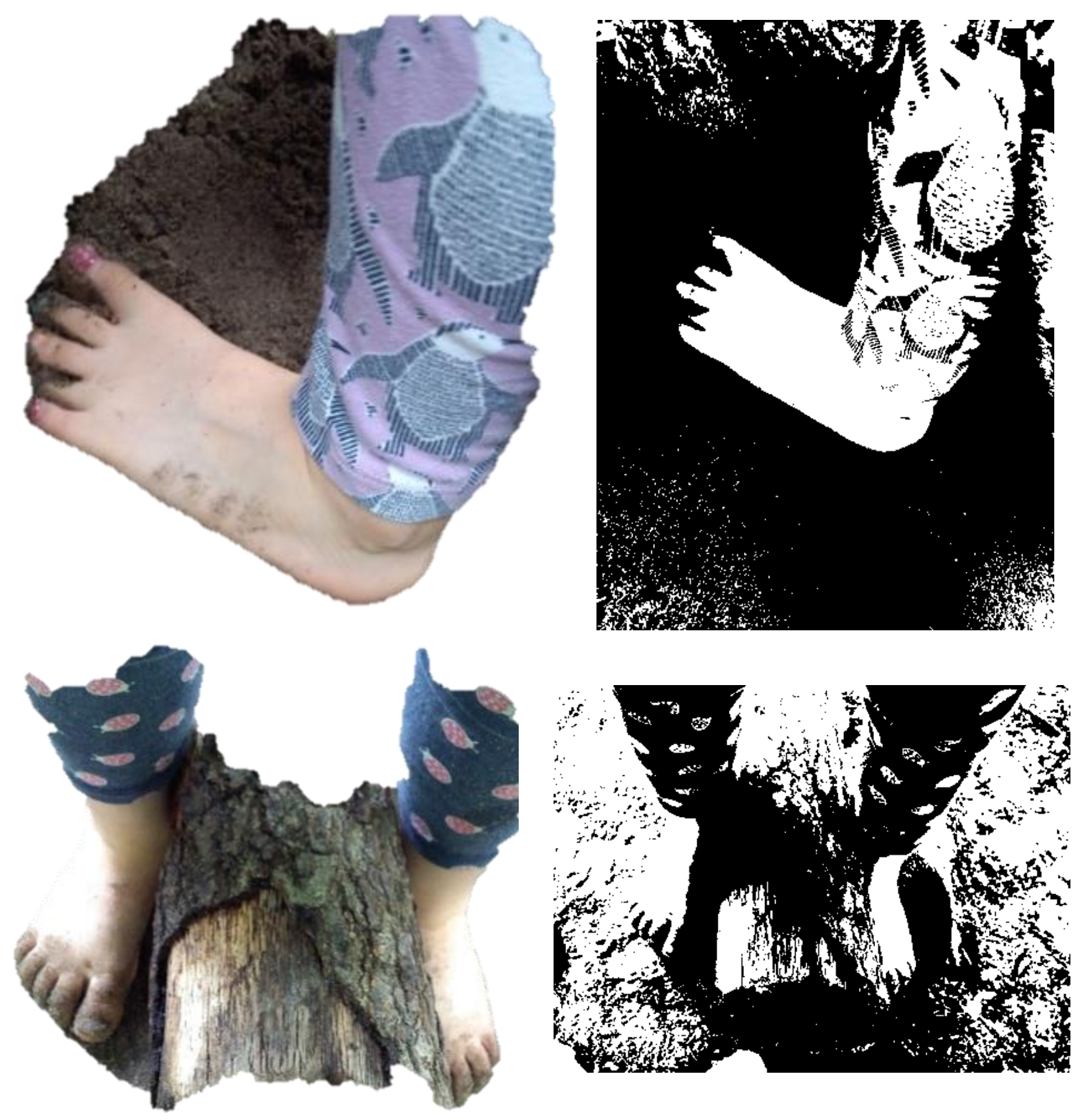

Figure 2.1. Monstrous relation. 


\section{Bare-foot Knowledges}

Cartesian knowledges run deep in early childhood. This can be seen by the field's dire need to justify play as learning in early learning settings. I often hear rationales that "through this type of play and inquiry, they [children] develop skills such as problem solving, creative thinking, and innovating, which are essential for learning and success in school and beyond" (Ontario Ministry of Education, 2014a, p. 7). While this article is not necessarily focused on this distinct aspect of curriculum, these observations speak to the general cognitivist and neoliberal inheritances of, for example, innovation, that we often carry with us when attending to documentation practices.

Ingold (2011) presents these stories of mind-focused rhetoric as not coincidental but rooted in historical descriptions of the aversions that privileged aristocracy had to engaging with bare-feet grounding (and walking in general), and later in representational logics that existed in identifying the mind as different than its relations with land (Jarvis, 1997 in Ingold, 2011). Travel attitudes in Europe from the eighteenth century onward were destination-based and perceived ground/land and physical work and walking as a lower status activity (Ingold, 2011). In early childhood education in Ontario, the closed, destination-oriented and representative ways documentation is used to prove or evaluate learning and thinking is so far removed from the ground/cellu-body relations we encounter with the playground. In my past work as an educator, I often wrote beautifully clean-cut stories about what each child did or created and I understood children as individualized cognitive bodies. The stories I created were required to have words or recollections of what the child was able to do and be. When I revisit these stories now, I trace how this worked to thoughtlessly present a direct insight into the movements in the educational 
space followed by a simplified purpose to why each child's movements were important. However, these stories were not capable of, for example, attending to the ontological messiness (and uncleanliness) of shoe-less movement and the way the shoe fabricates a divide or boundary between ground and foot - which parallels the defined boundaries between images of documentation and the event. Later in his works, Ingold (2011) thinks with various theorists such as Gilles Deleuze (2004) and Maurice Merleau-Ponty (1967) to relate to becoming-with as a continuous birth, or as moving along a line, rather than through closed representational rationalism. I entered this inquiry with an intention to move beyond a sovereign individualized human and representative categories for thinking documentation, and I wanted to attend to becoming-with. This is because I was concerned about the limitations that representational documentation holds in forming a particular kind of human and how representational documentation creates boundaries, segregations, and is limited by an unwillingness to think of different possibilities in regard to what a human and a moving in relation can mean. This also ties closely to the questions posited earlier about monstrosity because it defies the rational or cognitive into an engagement in moving and documenting with the world in un-determined, unruly, or un-planned ways. In order to open documentation up in relation or monstrosity, I wonder what types of human-nonhuman relations are possible when children's stories do not need to be pristine, segregated, and engaged only as they are stuck upon a wall or in a documentation binder?

\section{Becoming with-in attention.}

In considering the monstrosities of cellu-body relations, and attending to our inherited desire to separate human from land, it makes sense to think slowly about how we might create 
common/uncommon relations. For example, in our pedagogical inquiry research, we collectively discussed Paulina Rautio's (2017) work on a relationship with species of least concern by "listening to what the world speaks to us" as a "not-self" (p. 97) through Ingold's (2000) use of the word attending and Weaver and Snaza's (2016) notion attuning. In framing not-selves through attending and attuning as weaves of thought, I started to think about documentation in experiences. I was guided by what Spyrou (2018) describes as a shift from viewing the authentic voice of the child to a decentering of the child that "will allow the field to engage more broadly with issues and concerns which lie beyond its child-centered preoccupations" (p. 42). I thought about the many times I had compiled documentation to share the children's democratic voices, as if to uphold some kind of mastery of the democratic child in inquiry. I considered what this decentering would mean for the clean walls and binders in which we slapped on/in photographs to meet our documentation quotas. What would it mean to form pedagogical documentation in movement as monstrous, in relation with, and in attention with the sandbox, logs, and cold?

\section{Entangled Story Two: Documentation: The Conceptual, Material and Performative in Relation}

I came to our conversation about document with an uneasiness of the purposes of documentation that were inherited in neoliberal systems. I found documentation was used predominately to prove something, whether it be that a child has hit milestones or progressoriented steps, or the educator has completed some sort of duty that was often mandated by curriculum documents rather than by concerns of the educators in the space. As a result, I found I engaged in a filtering of my documentation to present particular stories of tokenistic happy humans that manipulated their environment and never had challenges, and I never paused 
wonder what this might mean. My concern was that documentation was a concept used to sell myself as an educator and the classroom as always working well, rather than a tool to create difficult and generative dialogue.

Documentation methods, or image making and reading practices, have been put under scrupulous examination by a wide range of scholars in a variety of disciplines due to their histories of colonial voyeurism that often represent a particular type of human (Edwards, 2012; Kind, 2013). For example, anthropologist Elizabeth Edwards (2012) argues that historical meanings of photographs reside in the relationships between consumption, ownership, institutionalization, and social accumulation (Poole, 1997 as cited in Edwards 2012). Similarly, Sylvia Kind (2013) has based some of her work in photo-documentation with children in response to categorization, regulation, and surveillance that have been historically used to support Eurocentric myths of authentic recollections of the savage (p. 427). There is a deep concern here about what it means to provide authentic documentation or recollections of human/nonhuman worlds, and how such practices of representation contribute to these violent colonial histories - and, to ongoing settler colonialism. It was with these histories that I chose to frame my concern with what it might mean to document in relation. For example, within this article, I am playing with picture format and gaze while engaging in an examination of conceptual photography (Soutter, 1999) where meanings are created within the object of photos themselves through a type of premeditation. I am purposely crossing and cutting boundaries in the photos (like Figure 2.1) in an attempt to present a cellu-body as a means to disrupt what Hultman and Lenz Taguchi (2010) describe as a human focused anthropocentric gaze. Kind (2013) also attends to this type of reconfiguration as she describes voyeuristic violent engagements in the language of photography-documentations by attending to the act of 
photography as a means of playing with and looking to possibilities of rupture within these inheritances. She states, "And so I wonder what it might mean not to erase the voyeuristic gaze and photography's histories, but to play with them" (p. 429). While seeing this type of documentation as one that is in rupture is important, conceptual photo-descriptions limit us to only attend to the representational features and disruptions of these features within the content of the photo. In thinking about the material use of paper and our current obsessions with representing and cognitively categorizing events in early childhood education, I was also drawn to think about what it might mean to consider human-centered rationalities that seek to consume and own materiality. Edwards (2012), for example, engaged in an agential material thinking in photography, as she described the role sensory experiences play in photo perception through orality, tactility, and haptic engagement. What would it mean to introduce oral, haptic, and tactical types of attendance in pedagogical documentation and how would it change the orientations of pedagogist-educator-child-cellular matter relations?

In their chapter called Reconceptualising Evaluation in Early Childhood Education, Dahlberg and Moss (2018) identify four ways in which documentation has been used to achieve particular types of goals which include: an assessment of democracy, assessing and evaluating learning, evaluating and challenging discourse, and evaluating vitality and intensity in event. Of particular interest to me is a vitality and intensity in event. Dahlberg and Moss think with bodies and theorists such as Erin Manning, Merleau Ponty, Whitehead, and Deleuze, to discuss worldings. They offer that "it is obvious that in this event something totally new emerges-the surprising discovery of another reality" (Dahlberg \& Moss, 2018, p. 3161). However, I approach this proposition with caution as it has the potentiality to, and often becomes, wrapped up and integrated in neoliberal discourse of quality-style production. I propose that in this case, human- 
centric product-oriented proofs of "what we did" and "what children are capable of" run deep, with the best of intentions in early childhood. This is seen in particular product-oriented, curriculum documents through phrases such as "making learning visible" (Ontario Ministry of Education, 2014a, p. 16) or sometimes to categorize and evaluate domain progression through "observation" (Ontario Ministry of Education, 2014b, p. 13). There is an interesting dance here between quality-style mechanisms to assess children's development (with repercussions of the elimination of diverse and bio-diverse knowledges) (Dahlberg \& Moss, 2004; Moss, 2010) and a humanist reflection on pedagogical thinking. In thinking again with becoming, this time with Donna Haraway (2008), where becoming-with is in relation with a particular context of what or who is at stake, I wondered what would happen documentation itself was framed as in movement, and as a prompt or provocation to attend to what it might mean to move ethically with paper and image in relation with feet and sand, as a cellu-body. Who is at stake in these relations? What if the relation in documentation itself were framed as a performative act?

I am guided by Karen Barad (2007) as she discusses performances in relation with material. She extends on Judith Butler's (1990) work on gendered performativity, as a series of fabricated acts and gestures sustained through corporeal and discursive ideas (Larsson \& Quennerstedt, 2012). By aligning performative acts with quantum shifts in the atomic theories of Niels Bohr, Barad argues for the shift to move away from linguistic or Cartesian representations of ordinal categorization (for example, cognitive/human/ primal/nonhuman and signifier/signified) to a performativity within agential realism, where human and non-human material are in intra-action. I propose that this kind of thinking would shift documentation from evaluation or representative proof toward perhaps attending to the ethics of our relations and toward generating many possible responses to material documentation/documenting. Perhaps in 
exploring materiality as relations, documentation with children could mean opening up documents in movement as an emergent corporeal experience, rather than the Cartesian representation Barad speaks about and that we know well in retrospective, report-like documentation practices.

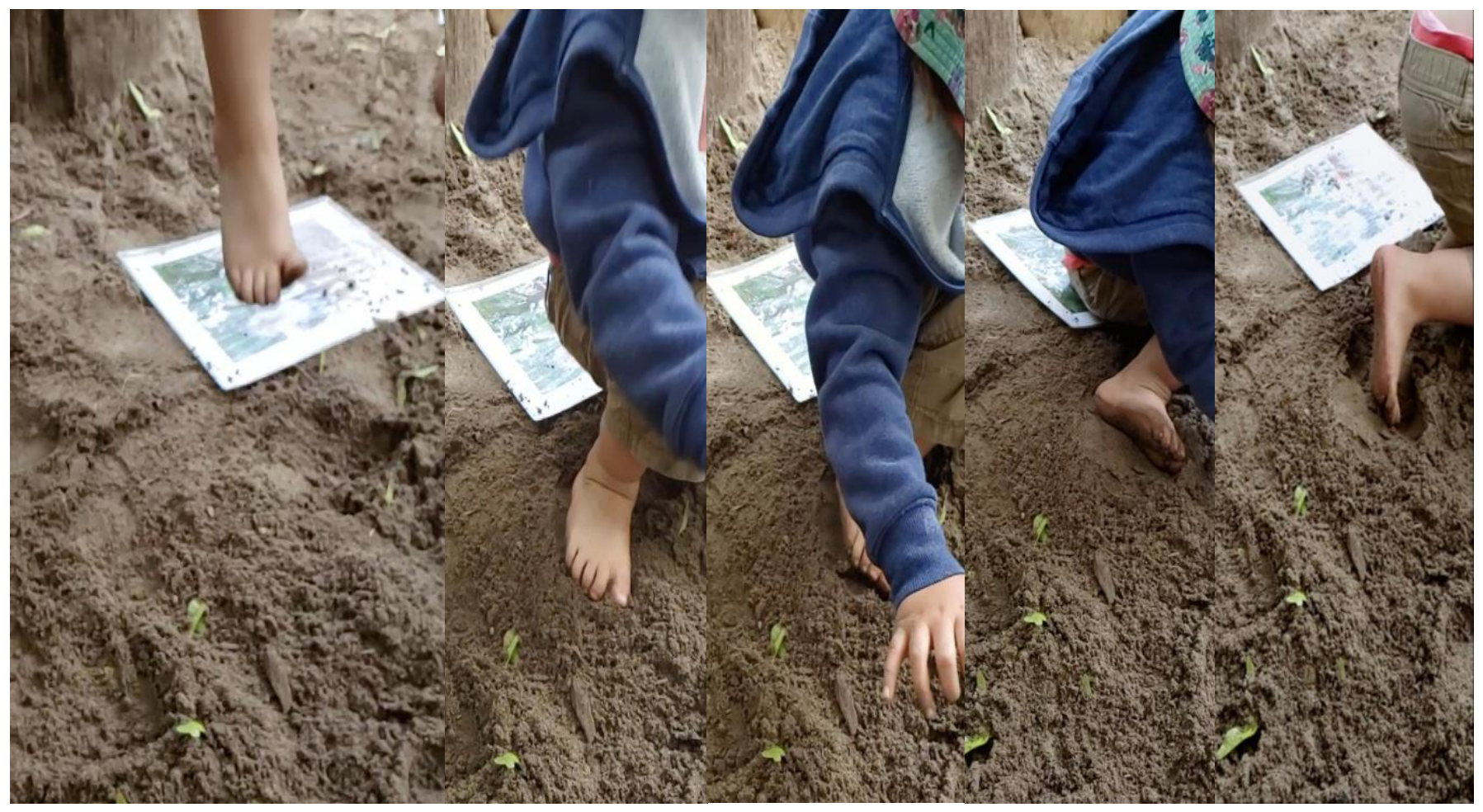

Figure 2.2. Moving with documentation.

\section{Moving with Documentation}

It was with thoughts around material-human dichotomies that we discussed the possibility of using documentation with movement in our pedagogical inquiry research. We wondered what it would mean to provoke our engagements with bodies as entities in relation if the photos we had created served as direct reminders in the sand box. We decided to print some 
photographs we had taken of the children jumping barefoot in the sand and bring them into the sandbox. Upon sharing these, the children noticed the photos situated in this space. They briefly discussed the photos conceptually by focusing on the contents of the photographs. For example, some children responded excitedly, "Look it's me in that photo!" or "We're jumping, those are the footprints." By exploring these conceptual gazes, I thought with Hultman and Lenz Taguchi (2010) to think about how "that is me" contributed to the Anthropocentric gaze. I continued to probe and ask, "What about the sand that is left behind in the photo? What about the sensations of the log?" After a while, consequently, or inconsequently, the focus on the photographs was shifted back to more shoes-off jumping activity. We noticed moments that these photographs were also in movement with the children. The photos took the role of sand gatherers as some of the children pushed sand onto them, and also as images in need of clean preservation as some of the children brushed them off. Interestingly, the photos were also used as slippery laminated landing sites in relation with the children's monstrous jumping (as in Figure 2.2).

The various styles of engagement and entanglement provoked some consideration about what it ethically means to relate with paper and dirty documentation. These moments started many conversations around what Donna Haraway (2016) describes as "staying with the trouble" (p. 114). In our case, this included cultivating a refusal to follow neoliberal, solution-oriented logics of moving past or fixing the paper/documentation problem quickly. For example, we wondered, what happens when children preserve documentation as something clean or untouchable? On the other hand, what happens when children engage with documentation in monstrous or against taken for granted ways of understanding movement? How might we think with the ethical implications of the tree-cutting, while attending to these logs through paper documentation (paper, made of trees)? These were some questions dancing around with 
conversations collectively, that made me curious to think with cellu-material as what Bruno Latour (2004) describes as a matter of concern. When I first built this concept of cellu-bodies and cellu-material, I was thinking back to the conversations with the children about a certain need to defend the trees. For example, we created stories about how we would save the trees from getting cut out and we discussed our desire to advocate on behalf of the trees. While this was an important concern, I wondered about the human-centred ways that stewardship narratives neglect various cellu-body relations daily, such as those with documentation (Taylor, 2017). Scholars throughout many disciplines have recently alerted stewardship narratives as ones entangled in enlightenment theory, where humans are separated from nature within a wilderness narrative by attending to it in certain consequential colonial human-serving ways that have led to our current environmental conditions (Haraway, 2008; Malone, 2016; Taylor \& PaciniKetchabaw, 2017). I wondered about cellu-body in documentation as a concept to put into question in how we exercise colonial ownerships over it, and neglect a more entangled or relational approach with documentation. Documentation and trees pushed me to wonder, "What does the concept stewardship do to taken for granted human-material relations?"

There is something also in border-making/breaking porosity that cellu-body thinking attends to as well. Border-making is physically and conceptually entangled with cellu-bodies. Our desire to define and categorize sovereign individualized dichotomies such as inside/outside, documentation/event, log/paper and human/nonhuman have consequences for condition-making in early childhood education spaces. As a result, framing these events as performative intraactivities (Barad, 2007) can create moments of disruption to the taken-for-granted borders we build around bodies, events, and documenting - or, following Colebrook (2014), a particular kind of monstrosity. 


\section{Entangled Story Three: Staying with the Trouble of Cellu-body}

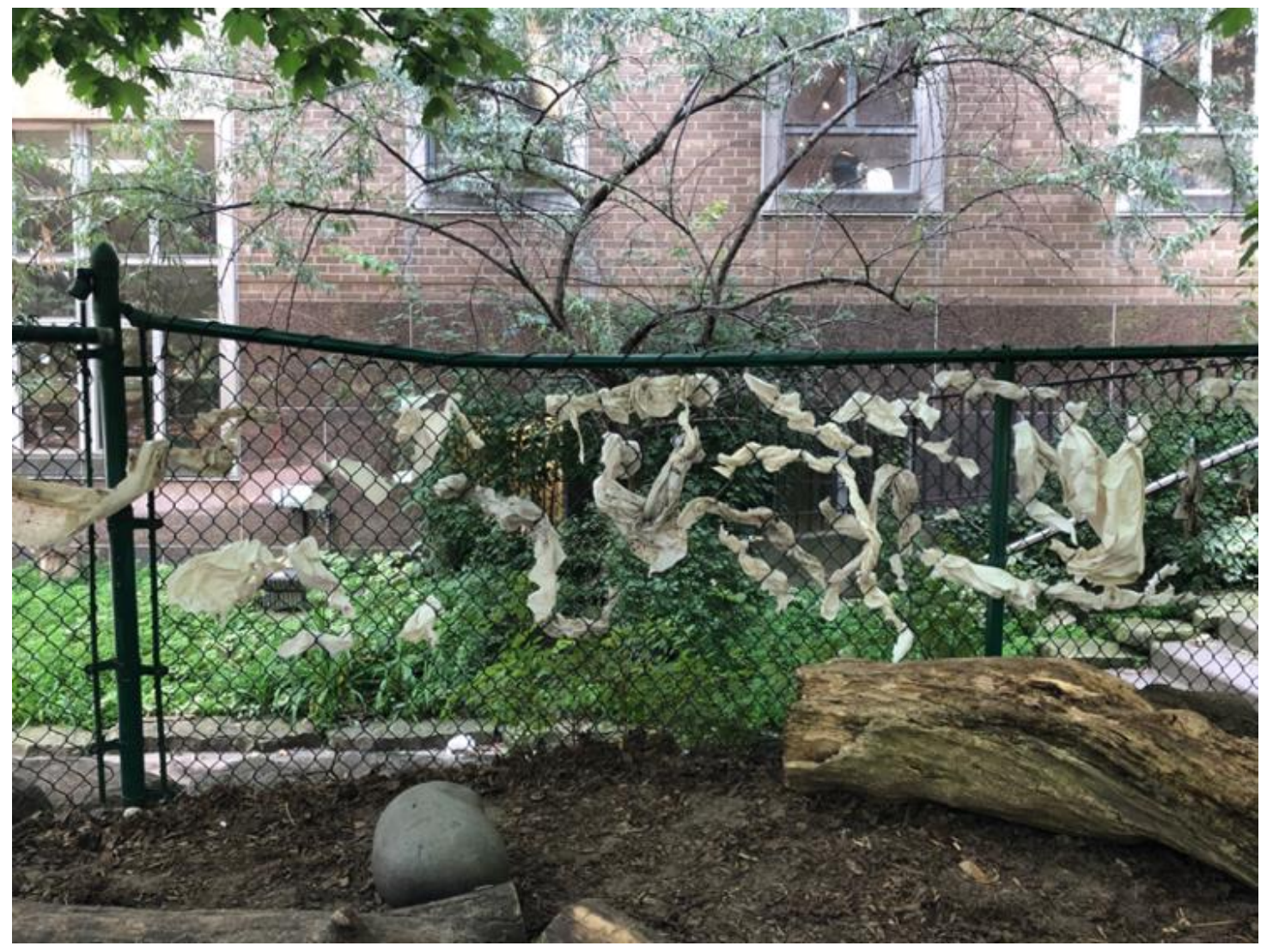

Figure 2.3. Staying with the trouble by weaving paper.

As we thought about the boundaries of our playground, in particular the fence, and the way the children related with the fence, we noticed how we paid little attention to the fence and what it does. Children threw materials over the fence where materials were forgotten. This was, for us, a moment of concern with these relations with boundaries. How can we live well together with the yard if the other side of the fence is an area of disposal? As a provocation, we thought about what would happen if we encouraged the children to notice this half-transparent chain link fence structure. We continued to think about how bodies currently move from place to place 
within the yard with little concern for boundaries and noticing. What would encourage this noticing? We thought about what it would mean for these borders to be less accessible or altered in some way. Would this promote that kind of attending and attuning that Rautio (2017) describes, where an attention to a not-self (the fence) would inform how we are in movement relation with it? To provoke this idea, we covered the fences with paper as a way of making this boundary more visible. As we covered the fence in paper, we witnessed children's hands crumpling up the paper and throwing it onto the other side: "We don't want it back, it's garbage", we heard. There were multiple conversations happening around the fence in response to concerns for what the "garbage" will do to surrounding animal bodies outside of the fence. To stay with this trouble, I noticed Nicole picking up the pieces and carefully weaving each paper through the wired grid of the fence (see Figure 2.3). I intentionally mandated my body to this space and the conversations and paper around it. At this point I was no longer obligated as an educator in the space to abide to surveillance and responsibility and I was able to engage in pedagogical questions with full attendance. I pushed myself to sit with these wonderings. My body initially did not comply, and my ears constantly brought my attention to conflicts and arguments in the background. This was challenging but necessary to acknowledge, and these body habits speak to the rigorous work and attention that is necessary when involved in thinking with pedagogical documentation. The children, researchers, and educators discussed the implications of throwing materials over the fence for many weeks. While some conversations involved an interest in what will happen to the animals, other conversations with children were related to how "we don't want to take them back with pee and poo on them" or "if we throw things over, we won't be able to use them". 
Narratives around destruction, I realized, are consistently perpetuated in early childhood settings. I thought back to the many times I engaged in natural consequence rhetoric with children in what this will mean for the human primarily: "if you break your toys, YOU won't be able to use them". There was something so troublesome and violent, consumptive and colonial about the alteration of a material and the connection this had to how we engage with destruction afterwards. What does it mean when we engage in the destruction and later label what we destruct as inferior and dirty or illegitimate? In thinking back to boundaries and their creation to identify illegitimate bodies, these narratives serve to promote a specific type of materialdiscursive power (Barad, 2017; Larsson \& Quennerstedt 2012), one that illegitimates or erases cellu-matter, I thought about the many times documentation gets put up and torn down and put up and torn down in early childhood classrooms as if the questions no longer exist and the material knowledges are not relevant. In a neoliberal and mechanical anthropocentric age of consumptive desires (Wolff, 2013), throwing out the tainted seems to be entangled in a narrative of fast paced ownerships. In thinking with cellu-bodies, I want to attend differently to destruction and its entanglements with pedagogical documentation: How might we stay with the trouble of monstrous movements that illegitimize cellu-matter? 


\section{Entangled Story Four: Performed Cellu-lines and Meshworks}

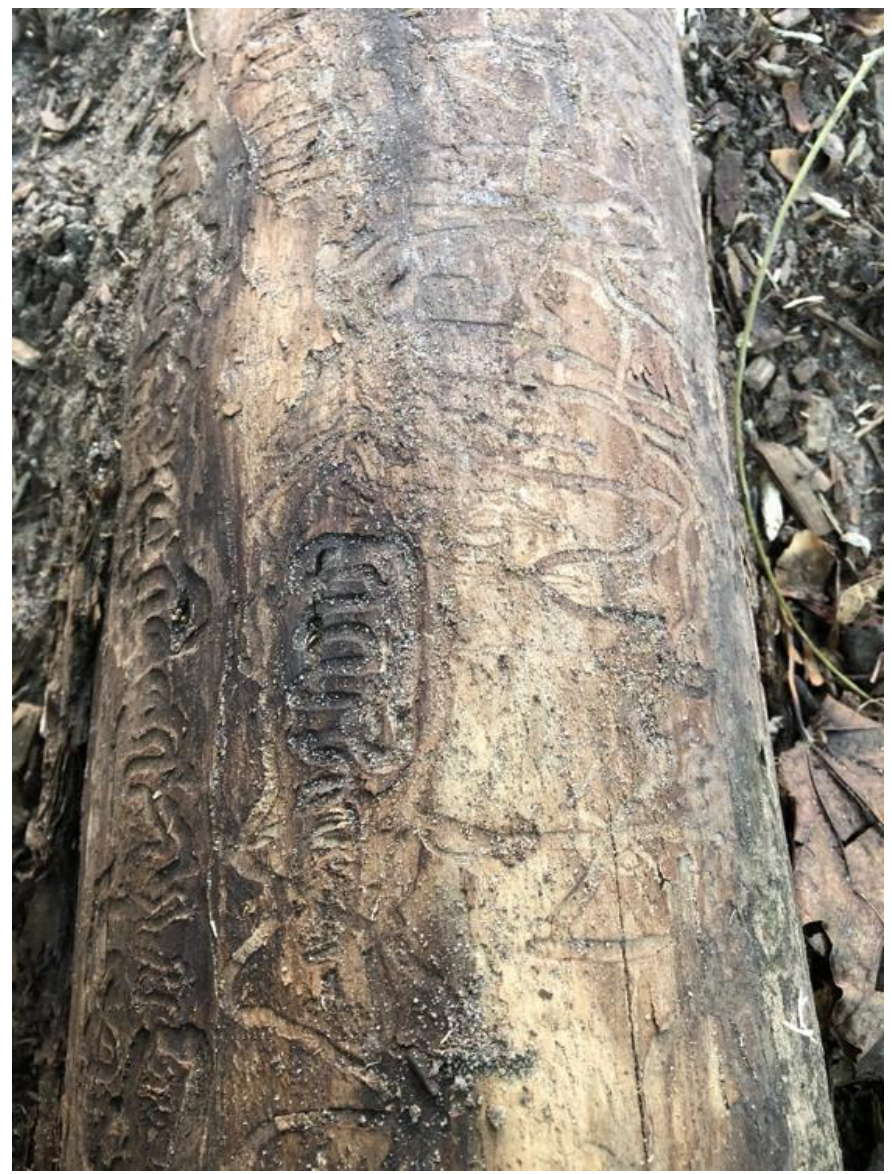

Figure 2.4. The path of unknowns.

"People [and non-people] are known [and unknown] by the trails they leave behind them"

$$
\text { (Ingold, 2011, p. 72) }
$$

The above image (Figure 2.4) is a glimpse into the logs left behind from... well I am not

quite sure where these logs came from. We stumbled on these prints while exploring and searching for insects with the children. We noticed the squiggly traces in which some creature made itself known or rather, unknown. The children and I asked together, "Where did these 
come from?", "Who created these designs?", "Where is this creator?" The children had a serious interest in where these creatures lived and where their home was. This was also amplified in the search for slugs and insects we had seen in the playground. However, while asking these questions I was also wondering if it matters that we name this path maker, and also what it does to name this path maker, or cellu-body. I am reminded of the boundaried ways that we have enclosed our thinking in the status-quo of early childhood education and of the way we strive to rationalize and know the unknowable subject. As Donna Haraway (2016) describes the failure of manmade biology practice to sustain biological knowledges, she comments on the "unthinkable: not available to think with" (p. 30) as a question worth attending to. Our path-maker was unavailable to think with through the logics we know well: naming, boundaries, ownership, sight. A biological logic of naming its habitat and identifying its species would not remedy this. For example, what human ethic is implied when we ask the question: "Where do they live?" This question can be approached through many identifications of ownerships and boundaries and narratives of who is allowed. With ownership and boundary logics we might conclude, for example, that the potato bugs live in the yard and in this log but not in our classroom or our hands. Are these observations that can help us to move well with this path-maker? Or do become inadequate?

A few months prior, I participated in an exposure with a group of pedagogists where we visited an exhibit titled The Life of a Dead Tree by Mark Dion. This exhibit spoke to the complexity of 'invasive species' by extracting them from a transported dead tree and posting them as what reminded us of wanted fugitive signs. Said to be harmful to both rural and urban biodiversity, invasive, and carried in imported timber from Asia, the Emerald Ash Borer (which I now believe to be the creator of these paths), is said to cut off water and nutrient supply of trees 
with its larvae. In the exhibit there are many wanted fugitive signs circulating that allow one to identify, label, and destroy these pests, but not many that describe the inherent systems that brought them there in the first place.

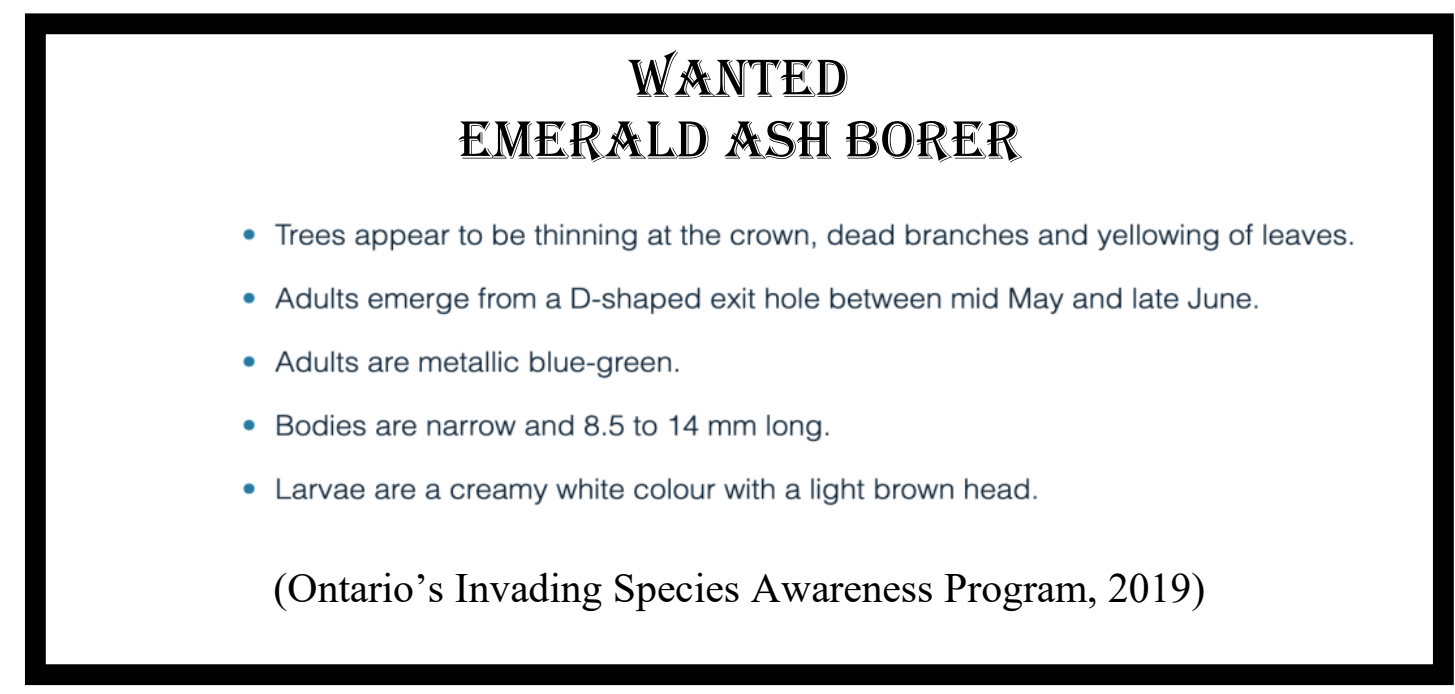

Figure 2.5. The Emerald Ash Border is wanted.

Forever labelled, this creature serves as a destructor in our human story (see Figure 2.5). This categorization creates a type of knowledge of good and bad species and leads to an ethic and action based on these relations of good and bad. Affrica Taylor (2017) describes this as the goodies and baddies. She advocates a move away from these categorizations, stating that

Ironically, the purer nature is perceived to be, or in other words the more it conforms to the wilderness ideal, the more compelling is the perceived need to protect it from human activities. This, in turn, bifurcates the humans into those 'baddies' who threaten nature and those 'goodies' who seek to protect nature from the baddies. (p. 1453)

The Emerald Ash Borer joins these baddies in the cultivation of a type of storying that makes the 'wilderness story' the matter of concern. During this time of noticing the pathways in the log in the playground, we never found or labelled the culprit of the tree's carvings. However, the path 
left behind by a possible invader speaks to our initial wonder about the cut down trees. In the name of what are we cutting down trees? In this case, following paths directs us to a not-self, and perhaps a not-self, that is woven in with other beings. It was important for me to trace this, because as this critter is villainized, a not-self, could disrupt romanticized practices of documenting with paper and cellulose and implicate us in this destruction through our own documentations and material use and would perhaps start to break down these labels of goodies and baddies that are inherent in colonial and neoliberal ways of knowing.

\section{Performancing and Meshwork Formations}

"Nobody lives everywhere; everybody lives somewhere. Nothing is connected to everything is connected to something” (Haraway, 2016, p. 31)

Karen Barad (2007) discusses the illusion of the knowable subject through a Cartesian representationalism. Representing, identifying, categorizing, describing, and engaging with this particular subject/creature makes the illusion of a fully knowable subject. I propose, that in considering this particular event of meeting the log with pathways, as a performance of documentation left behind, there is an alert to the unknown. There is a different way to see traces, beyond how they can be categorized. I am reminded of Tim Ingold's (2011) approach to "meshwork" (p. 84). The meshwork is composed of many lines of life that cross over each other but never connect. In the meshwork, the lines are never in the same point together, never at a complete consensus or understanding of another line but are sometimes bundled together as “knots" (p. 71). Donna Haraway (2016) has pointed to these lines in using the term tentacularity. As a beautiful metaphor in of the work of attachment and knotting, she writes, "the inhabitants of the world, creatures of all kinds, human and non-human are wayfarers; generations are like a series of interlaced trails." (p. 32). If we propose that there are no individualized, sovereign child 
or adult bodies but only relations and spaces in between, we start to see this space in between cellu-body; cellu-insect as knowable and unknowable, common and uncommon at the same time. Lines of being interrupt, engage, and intra-act between time-spaces. In an effort to open up and create other possibilities of being-with, I have strived to think with documentation as performativity for this reason. Rather than thinking with how to represent what it is we are looking at in objectionable terms, what would documentation look like in moving-with? Donna Haraway (2016) cultivates Felix Guattari and Isabelle Stengers' notions of thinking as a thinking-with, as a way of "relaying" (p. 34) but also a thinking in between. As children moved their fingers through the lines on the log and then quickly pulled them off in search for the insects, I wondered what it would mean to as Haraway says, stay with the trouble and with how we can think in between these particular patterns. Because these patterns exceed our known ways of perceiving as knowing, I suggest that they complexify our reliance on human exceptionalism, categorization, representation, and boundary-making in documentation. Rather, seeing this log as an act of performativity between the critter and the log, complexifies our known ways of moving in early childhood education as a tracing of these performativities as documentation, unrepresentable in a unitary subject way, but perhaps in a more collective way of moving in a meshwork.

\section{Final Thoughts}

We are all implicated in non-innocent representational logics. This article is an excerpt of my own thought patterns and responses to our ongoing particular pedagogical inquiry work. However, reframing documentation as a performative act has afforded the opportunity to notice the unknown. Or rather, to notice that we are shielded by the unknowable and to address particularly unsettling practices in early childhood education. In attending to cellu-bodies, I think 
with monstrosity and performativity in documentation as boundary crossings that destabilize the unitary subject. Opening up documentation practices as performances allowed me to think about material (cellular material) deeply as an ethical relation that aims to disrupt common presumptions about what it means to document (especially with paper) and how we attend to the documentation as sometimes destructive. I am not interested in this article in providing the next best practice in documentation. Rather, I suggest carefully attending to the events that are ethically entangled with documentation. I tentatively ask and offer forward some questions to consider in early childhood spaces: Who/what is allowed to document in moving in early childhood education? What counts as documentation? 


\title{
Article 2: Uncommon Relationships - Moving Within a Meshwork
}

\begin{abstract}
This article follows me (an educator/researcher) through an ongoing pedagogical inquiry project. I situate children's and more-than-human outdoor movement and activity in an early childhood education centre playground by framing it through Tim Ingold's notion of the meshwork. In using a common worlds pedagogy (Common Worlds Research Collective, 2019) together with Cadena and Blaser's (2017) notion of un-commons, I work through two story examples of moving with children, logs, rats, mushrooms, slugs, and worms. My analysis speaks to how relation-ship and communication with more-than-human worlds can be understood in complex, entangled ways within a meshwork.
\end{abstract}

Keywords: movement, environments, common worlds, uncommons, meshwork, early childhood education 


\section{Introduction}

The following work is based on an ongoing early childhood education pedagogical inquiry research project that draws on the question, Why do we care about movement? Located in a downtown Toronto early years setting, this article follows my transition from a researching educator to a researching graduate student and draws on collective conversations with Dr. Nicole Land, the educators in the entire centre, the educators in the classroom where I was an educator (Andrea Thomas, Maria Wysocki and Selena Ha17), and various discussions and experiences I have had with pedagogists and the surrounding early learning centre community.

Throughout this research and this article, I seek to disrupt understandings of humans as bounded, sovereign individual subjects by thinking with storytelling as a "storying that cannot any longer be put into the box of human exceptionalism" (Haraway, 2016, p. 39). I take up storying in this way in response to the human-centered, extractive, consumptive, and violent ways settler colonial, post-Enlightenment Euro-Western ontologies and the concurrent nature/culture binary have taken up relations with more than human worlds (Taylor, 2013, 2017; Taylor \& Pacini-Ketchabaw, 2017). I seek to engage in inquiry through a decentering of the child (Spyrou, 2018) and the logical humanist subject (St. Pierre, 2000) by inquiring with children seriously in relation with more than human worlds. I am inspired by Tim Ingold's theorizing using Marleau Ponty's (1964) concepts of world in formation to find moments in our pedagogical inquiry that generate opportunities for thinking in relations as a world that is not finite and complete, but a relation that contributes to a world in formation (Ingold, 2013).

17 In this work I have named the educators I have worked with because I wanted to emphasize the important roles they played in collective conversations. They have signed consent forms and I have also spoken with each educator to gain permission a second time and show my gratitude for thinking with me in this project. 
I begin with a discussion of commons and un-commons as well as with Tim Ingold's use of the term 'meshwork' as a way of storytelling my way through the unitary sovereign human subject. I then think with an event within the playground where we thought with 'ratty movements' that led me to think with awkward 'species of least concern' (Lorimer, 2014 as cited in Rautio, 2017) as a practice in disrupting unitary, humanist subjectivities. Following this provocation, I think with two stories where I intervene in conceptions of the unitary sovereign humanist subject by thinking with communication and relationship within meshwork while I work to disrupt romanticized notions of how connection is taken up in early childhood education.

\section{Thinking with Commons and Un-commons}

The pedagogical inquiry research that I think with in this article draws on a central question of what it means to move/live well with others (Vintimilla, 2018), and to think with movement "carefully, critically, and pedagogically" (Land \& Danis, 2016, p. 27). Inspired by a common worlds pedagogy (Common Worlds Research Collective, 2019), our pedagogical inquiry work experiments with creating a collective 'worlding' in order to attend to nonhuman worlds and relations (Taylor, 2017). A common worlds pedagogy is inspired by Bruno Latour's theorizing that" [speak]s about the necessity to reassemble all of the constituents of our worlds including nonhuman life forms, forces and entities - within a radically expanded conceptualization of the social" (Latour, 2005 in Pacini-Ketchabaw, Taylor \& Blaise, 2016, p. 150). Additionally, I am also inspired by Cadena and Blaser's (2017) use of the term (un)commons, where they argue for "committing to a mutual transformation without equivocation" (p. 192). It is with this commonality within (un)commons that I approach the various conversations and provocations throughout my time as an educator-researcher and then student researcher in our inquiry work. I propose that understanding commons as simultaneously 
(un)commons broadens the field of possibilities in how we see movement connection or relationship with more than human worlds. I then layer upon this the complexities of thinking with meshwork (inspired by Tim Ingold) and return often to Donna Haraway's (2016) suggestion that we might move with the unknowable or what is made "not available to think with" (p. 31) through humanist logics as I work to tell a story that moves beyond human exceptionalism.

\section{Onto-entanglements With-in Meshwork}

The research is situated in the playground, otherwise known as the outside of the urban childcare centre. Often in early childhood education, we think of outside spaces as specially constructed structures that are readily available for children's gross motor activity. Underlying these thoughts is a presumption that the outdoor place is solely available for the unitary child subject, who is positioned to consume, own, and master this expertly fabricated space. This presumption is also characterized by the romanticisms that form when we discuss children and nature in interaction. As unitary bodies children and nature remain separate (Taylor, 2013), and these distinct categorizations pronounce the us and them, creating boundaries and categorizations of what constitutes the other. As a commitment to refrain from taken-for-granted familiar ideas around outdoor environment and the bounded, cognitively represented, categorized individual that we often encounter in early childhood education discourse, I think with Ingold's (2011) question of what it means to be alive within an entangled meshwork and what this means for relationship building with each other and with more than human worlds.

Ingold (2011) describes the unitary human and its perception of the non-human as object, as what he names the inverted individual. Illustrated as a closed circle, bound and closed off to entanglement with another, it is with an inverting of this inversion that Ingold thinks about movement, social relations, and storytelling. With Erin Manning (2009), Ingold proposes 
thinking of life along a path and reiterates that "life (or thinking) does not betoken movement, rather it is in movement that life exists" (p. 72). Additionally, Ingold describes movement alongside Deleuze's proposition of lines of flight, where each being moves and is composed along a line or bundle of lines (Deleuze, 2004), or as Ingold labels - knots. For Ingold, it is the purpose of an inverting inversion to resist points of origin and rather to move and live in becoming or worlding. This rephrasing of noun to verb (becoming, worlding), animates relations in stories and moving through place as relations that are in making rather than defined and objective.

Ingold (2011) argues that by attuning to becomings and worldings we can disrupt humananimal/material categorization and humanist hierarchal cognitive representations. In this paper I propose picking up Ingold's propositions with relationship and movement in early childhood education. I believe that in early childhood education this is relevant to the hyper-categorizations that exist in status-quo movement pedagogy. For example, thinking of movement pedagogy as segregated only within the realms of designated times (durations) and movements (gross motor skills), and for the purposes of an individual child's socialization or obesity prevention limits moving-with another to activate an ethics of response-ability (Haraway, 2016). By using the word meshwork, Ingold responds to what was initially a series of connections in the actor network theory (ANT) of Bruno Latour (Ingold, 2011, p. 84). He argues that ANT has been taken up within the interactions of unitary people and the unitary "objects in which they deal" (p. 84) (which he remarks is a concern for Bruno Latour as well). As a result, Ingold's term meshwork, borrowed from Henri Lefebvre (1991), is explored through a metaphor of a spider weaving a web from its own body that is directly/and indirectly in relation with the fly. The spider does not know, and I would suggest move with, the fly through a direct interaction, but 
through the relations of the vibrations that exist within the web that they are a part of. These two human constructed categorical entities (fly, spider) are in what Ingold describes "conditions of possibility" (Ingold, 2011, p. 85) rather than perhaps through categorizations of two bounded individuals in very particularly enforced relationships with each other. Through this web, Ingold starts to describe a meshwork where subjects become entangled and woven into a texture. Created by moving along lines, meshwork is introduced by a Deleuzian haeccity, or bundle of lines which Deleuze and Guattari have illustrated as a rhizome (2004). Deleuze and Guattari have described this idea using the roots of a potato that grow in multi-directionally. Within the rhizome, there is no initial start as the roots are always in-becoming. Ingold suggests a comparison of the rhizome, or haecceity, to the mycelium as starting from the fluid character of life process, only bound by the flow of these materials. It is this fluid character that is of importance to Ingold, and perhaps as a response to unitary bounded subjects, as he explains, "the fluid character of the life process, where in boundaries are sustained [are] only thanks to the continual flow of materials across them" (Ingold, 2011, p. 86). As lines of flight move through and bundle together, they are in relation through their fluid character (as the spider and the fly, or a child and a mushroom - a story that I will tell throughout this article).

This description of moving within the meshwork is one that I will refer to as I consider moving with place throughout this article, where I question how we might move with matters or species of least concern. In this article, I integrate knowing place in a meshwork within a common worlds approach (Common Worlds Research Collective, 2019), while perhaps complexifying the notion of connection in the actor network theory by questioning what it really means to be completely connected at a single point, in a full realization of the other and whether this is even possible. I wonder, throughout this work, what possibilities are available for 
connection and relationship and how relationship can be discussed beyond its romanticized function in early childhood education. Resultingly, I think with relationship and body communications as complex and perhaps in un-commons. It is with this thinking that I hope to create a disruptive opening against the human essentialist stories Haraway (2016) describes as taken-for-granted responses to the catastrophic environmental events that we are currently all entangled with. The stories I tell are woven rather than separate or sequential and, as Ingold describes, composed of a gathering and knotting of threads of life in early childhood education.

\section{Initial Pedagogical Discussions and Provocations}

To begin, my educator co-researcher colleagues and I came together through a deep interest in what it means to move through the playground. We (Maria, Selena, Andrea, and I, with Nicole) met once a week and engaged in pedagogical discussion around these concerns, and we enlivened our conversations and questions on another day through offering a provocation we thought through with the children. We were interested in recently cut down trees that became logs we inherited. These trees, which grew on a street near the early learning centre, were said by the university to have been at risk for invasion. The logs were transported into our playground where they served as sites of jumping and gross motor movements. This led to a long inquiry into boundary making in relationship with categorizations that included rules, quota systems, and ownership in our playground as children participated in excluding each other using logs. We (educators) discussed the way in which log jumping had been taken up romantically while avoiding the reality that these were cut down trees from around campus. One way in which we explored boundary making was in the divides perpetuated by romanticized and modernist efforts of the Western Enlightenment era that separate nature and culture. Pacini-Ketchabaw and Nxumalo (2015) explore this in, for example, raccoons, whose 'unruliness' and boundary 
crossings unsettled early childhood spaces and the colonial histories that were intended to hyperseparate nature from culture to facilitate economic progress. I began to think about our questions of boundaries alongside Ingold's (2011) proposition to invert the inverted bounded individual whose classification limits possibilities for moving with another.

A few months into our inquiry, and during the time where I had transitioned out of the role of an early childhood educator into a student researcher, the educators in the playground noticed a tension in rat extermination. The playground was surrounded with rat poison to protect the children from these animals. Dead rats became part of the playground, as rats ate the poison and died in the play space. We thought about what rat death meant in the playground with Narda Nelson (2019) who states,

What if, for example, we discuss ivy and rats as being creatures that colonizers brought with them to this place? However small this act may seem, perhaps doing so might open up space for new conversations and perspectives that might not otherwise happen if we continue simple refer to them as 'invasive species' outside of the histories so profoundly shape this place. (p. 15)

When I put our thinking with rats into conversation with our thinking with the cut down trees and my thinking with Ingold's meshwork, I became concerned with the redemptive story telling that led to overlooking these species. It is with these ratty concerns, the invasive tree species that presumably were said to be the cause of the cut down trees, and a desire to care with 'species of least concern' (as Rautio (2017) speaks of), that I sought to move with the "baddies" in our playground (a term described by Taylor, 2017). Usually, playgrounds are seen as a 'pure' or protected space where baddies and goodies are divided and boundaried (Taylor, 2017). For example, healthy grass is good for providing cushioning for children's gross motor skills while 
damaged grass is bad as it requires care and maintenance, squirrels are good and cute while rats are filthy and dirty, cut down logs are good to promote gross motor and a connection with 'nature' while unnecessary trees are bad and are disruptive in scanning and surveilling the playground. Thinking with Ingold (2011), and with my desire to disrupt the sovereign, individual subject, I wanted to attend with children to baddies because of the extractive and violent ways this binary and human-centered logic has served to undermine species of least concern in the age of the Anthropocene. I wanted to think with response-ability through a care and remembering of who lives and dies in the playground (Haraway, 2016).

\section{Mushroom Traces}

"Mushroom tracks are elusive and enigmatic; following them takes me on a wild ridetrespassing every boundary" (Haraway, 2016, p. 137).

Mushrooms can be sometimes seen as 'baddies', following Taylor (2017), in childcare. The poisonous mushroom glooms daily on educator minds and results in consistently timed playground checks as bodies claw through fungi with big steel shovels and discard them into plastic garbage bags. Within my work as an early childhood educator, mushroom extermination was a daily process in my morning scan of the playground, followed by the collective frustration between educators when "they just kept growing." Group discussions were often made between educators about the necessity of this destruction followed by concerns about children's eating practices and their tendency to put things in their mouths. "What if they're poisonous?", we worried. In this case an accountability to the child directly engaged me in an avoidance of my response-ability to/with mushrooms. With little knowledge over the actual details of this particular species of mushroom, these stories of accountability and the fear they caused directed 
us to refrain from any careful attendance of the mushroom's existence. No one wants to take on THAT responsibility, we said; we're simply not the right experts, we repeated. I am reminded of a quote Nicole shared with me by Donna Haraway (2016) in all this mess:

there is no innocence in these kin stories, and the accountabilities are extensive and permanently unfinished. Indeed, responsibility in and for the worldings in play in these stories requires the cultivation of viral response-abilities, carrying meanings and materials across kinds in order to infect processes and practices that might yet ignite epidemics of multispecies recuperation and maybe even flourishing on terra in ordinary times and places. Call that utopia; call that inhabiting the despised places; call that touch; call that the rapidly mutating virus of hope, or the less rapidly changing commitment to staying with the trouble. (p. 311)

And in this non-innocent ordinary place, how do we (interested in early childhood places) attend and move with the fungal baddies of our playground with care, rather than with universalisms and erasures that perpetuate colonial and destructive relations and thoughtlessness in everyday moments (Haraway, 2016; Woods et al., 2018)? If the mushrooms were indeed poisonous, how might we stay with this trouble and interrupt these small practices of killing and making invisible that we engage in in early childhood? 


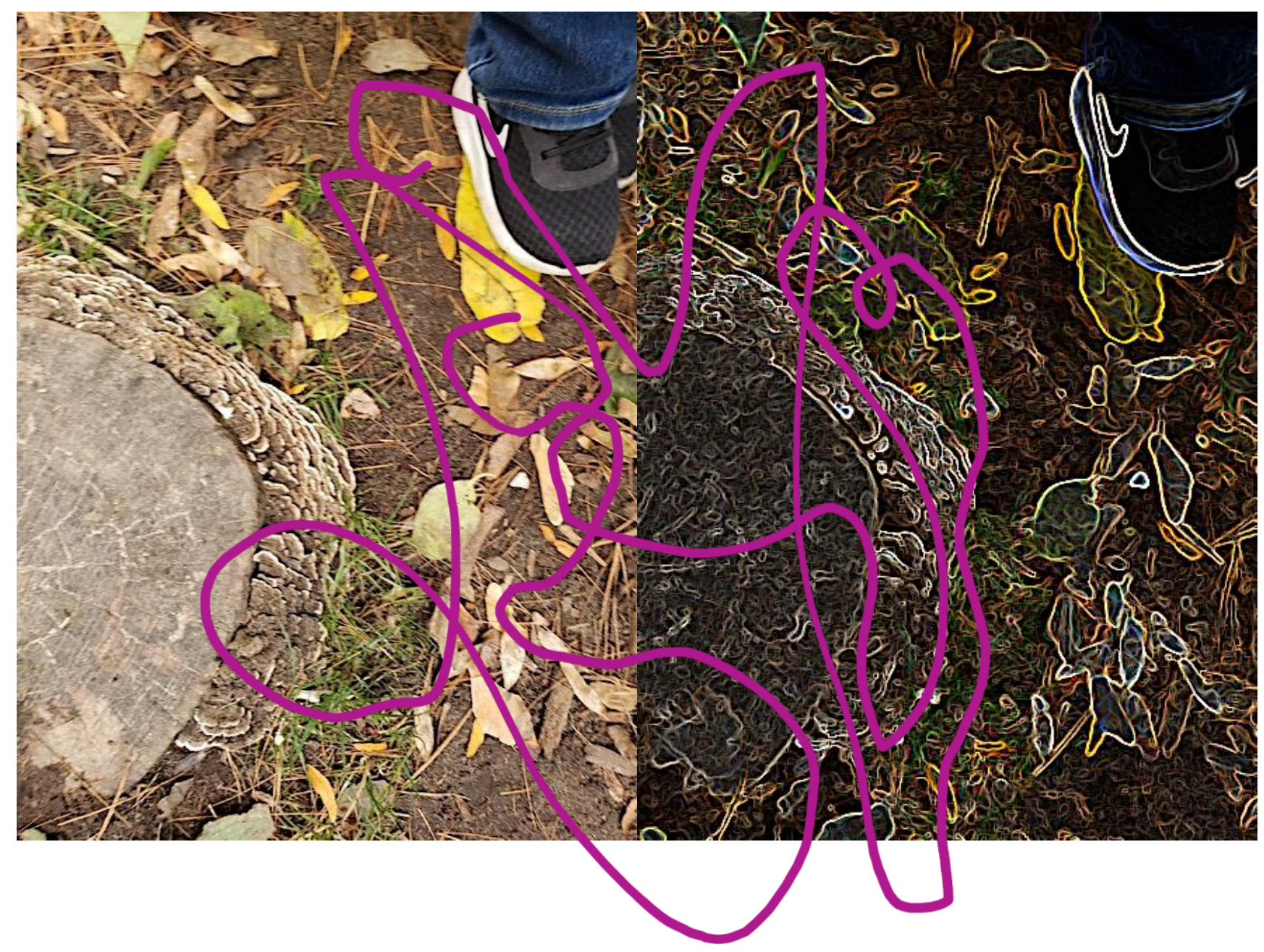

Figure 3.1. No boundaries and the mushrooms we can't see.

The children and I stumbled on these particular fungal growths (Figure 3.1) one day, as their intricate patterning and colouring rested on the log. I started to take pictures with my phone camera and the children gathered around. My partners in inquiry engaged in what I could interpret as a stomping pose. Knees were drawn, as children were ready to engage with (what we might see in taken-for-granted logics as) gross motor skill development on the mushrooms. I shared their desire. There is something exciting about the gentle crunch, perhaps the sound, texture, smell of a mushroom, that draws me to explore its sensorial properties. Beyond this, scientific logics have informed us that the mushrooms do not feel pain, that the destruction of the 
mushroom does not negatively impact the fungal 'meshwork' or mycelium (Tsing, 2015). I am provoked by Anna Tsing's (2015) consideration and contemplation of her practice of how to love a mushroom in hyper-capitalism and destruction. As baddies, mushrooms are in early childhood, as in other spaces, often neglected and forgotten unless they provide consumptive value. Because we see so little of the mycelium, we dismiss the idea that indeed we are with-mycelium constantly. Maybe the implication of introducing ourselves to this fact of living with mushrooms is more complex than only seeing what appears.

In this moment with the children, I wanted to disrupt the 'fastness' or thoughtlessness in movement that we sometimes experience as children move from one activity to the next, by trying to refocus a different kind of attending with the children. I continued to kneel down and watch with my camera. I shifted my body in order to make it more difficult to simply jump on the mushrooms or engage in jumping relations with mushrooms. "What is it?" one of the children asked. I responded, "I am thinking about the way the mushrooms speak with each other, and with the trees and our playground." This created some puzzlement, "If they can speak, why aren't they moving?" someone asked. "Why don't they have mouths?" This created some wavering, as I responded, “They don't speak like you speak, but the trees change when they are there, and so do the mushrooms." A child asked to take a video with my camera and moved it back and forth, as if the mushrooms were 'speaking'.

I want to consider this question of mushrooms' movement and communication within the way Pauliina Rautio (2013) has referred to taking children's ideas seriously in researching and attending with non-human entities. My own reservations and fears about mushrooms not being available to think with through humanist knowledges, as Haraway (2016) proposes, came into tension with the sensorial and scientific logics of exploration. In a taken-for-granted scientific 
and sensorial exploration, the mushrooms are simply there to be labeled, hacked, opened, and categorized. Donna Haraway (2016) describes this in the context of scientific knowledges that hold to visions of individual human selves creating the 'best' biological insights, as she explains that these scientific ways of knowing "no longer sustain the overflowing richness of biological knowledges - if they ever did" (p. 30). However, this idea of movement and communication that was posited by the children led me to think with how we might attend to communication and relationship with more than human worlds, perhaps beyond ideas around the extractive work of exploring or destroying unitary mushroom bodies. How might we attend to connection or relation-ship in more than human worlds? What would it mean to learn with/in movement with fungi? And in thinking about the destructive relationships and boundaries that hyper-capitalism and neoliberalism have inflicted on vulnerable more-than-human populations, how do we approach fungal communication as what Donna Haraway (2016) describes as "unavailable to think with" within the context of humanist science, and with what Ingold (2011) describes as a "shuffling between the ecology of real with phenomenology of experience - a life that overflows boundaries" (p. 23)? What does it mean to notice moving with fungi in intra-active ways (Barad, 2007) or as an approach that refutes human and non-human boundaries and acknowledges constant diffractions and exchanges present in these moving relations?

Fungi is interesting because it comically surpasses all human-made boundaries. When we move with the playground, we move with mycelium not as individualized sovereign subjects or as Ingold (2011) would describe, inverted bodies, but perhaps as movers and contributors through a meshwork, weaving through webs, knots, and entanglements. While, with scientific and human-centered approaches, we refer to some fruiting bodies (mushrooms) of mycelium as individual bodies, mycelium's porous reproductive tendencies, as well as its attachment to the 
connected and complex entangled underground and above ground worlding relations of spores, mycelium, sweat, skin, cellulose, and soil become overlooked. It is within these complex entanglements that bodies are sometimes not even able to attend to others, Anna Tsing (2010), for example, describes the sound of spore release as unavailable to the human ear.

Communication and relationship with more than human worlds start to become common and uncommon here as individual bodies are un-knowable. An acknowledgement of the entangled ways in which the fragments that make our bodies move with fragments that make mushrooms, spores, and mycelia alerts me to think differently about what engaging really means. We can no longer discuss an interaction or mastery of the child in connection or expression with the mushroom, rather these lines of life are in meshwork, (in)dependent with each other and unknowable.

\section{To Label or Not to Label - Contemplating Communication \\ In 'movement'.}

In early childhood education, one taken-for-granted human-centered narrative of movement is witnessed in self-expression and communication. Both early learning documents contextual to Ontario, where this pedagogical inquiry research took place, incorporate movement as expression. While the Early Learning for Every Child Today document, a developmental inventory, is predominately concerned with following patterns or working through moods as becoming 'expressive' (Ontario Ministry of Education, 2014a, p. 53), How Does Learning Happen puts this within the expression category that "enhances creative problem-solving and critical thinking skills and strengthens their memory and sense of identity" (Ontario Ministry of Education, 2014b, p. 42). In considering the neoliberal knowledges implied in humanist narrative

of identity and developmental progression - logics that have led to the catastrophic destruction of 
species - I would like to put the role of identity into question beyond ideas of representation where representations are created and distributed by the sovereign human being to express their identity in logical, human-centered ways. A collective way of moving and expressing together would need some other logic to think with, some other way to attend with livelihood beyond Cartesian logics of mind/body splits that imply we can logically find solutions to complex questions cognitively and categorically (Ingold, 2011) and that hold that the purpose of children's movement is for a progression of this cognitive ability to properly do expression.

Returning to the moment of finding the mushroom with the children, the question the children asked, "If they can speak why aren't they moving?", is relevant to my suggestion that representational knowledge fails in moving with other. When we exercise inversions and humancentered logical reasoning, do we have the capacity to move with others? I find this question interesting next to the woven knots of lines of flight in Ingold's (2011) meshwork and the many theorists that have contributed to this proposition. As Ingold's meshwork does not begin with a unitary subject but as an architecture, already woven into moving/becoming lines, our image of the social child/human is vastly interrupted. As described earlier, Deleuze and Guattari's (2004) lines of becoming are not defined by points of connection, but through a passing through. Ingold (2011) suggests the lines do not connect; we as bodies of moving meshworks cannot fully know or connect with the fungi in a romanticized communication but can weave and move in between the lines that make up fungal bundled bodies, altering our own paths as wayfarers. This means that, as we move with the mushrooms in the yard we are moving alongside the mushrooms, and are maybe uninformed by the many ways they may be changing our paths and entangled with us on the playground. 
This leads me to my next question on how to respond to the age of an Anthropocene - or Donna Haraway's (2016) more political description of a Chthulucene as human and nonhuman species linked through tentacularity. Is noticing our more-than-human relations enough as we work to move well with the playground in these precarious times? Or rather, what kinds of noticing are needed to disrupt the sovereign humanist individual? As Anna Tsing (2010) offers, how do we love a mushroom in ways that do not just focus on how they are useful to our existence as human species? How do we love a mushroom in a time of extinction (Tsing, 2010)? What kind of noticing is required and how might we cultivate these ways of noticing with children?

\section{How do we notice body and mushroom?}

Anna Tsing (2010) describes noticing mushrooms by drawing on taxonomy as she responds to common disciplinary trends of moving away from classification systems: “... it is easy to feel the pleasure of naming. Here, through nam-ing, we notice the diversity of life" (p. 142). Indeed the tracking of mycelium's fruity traces, or the blooming mushroom, points to the existence of something other because it gives us traces or starting points to engage in curiosity. I however wonder how noticing and labeling that is involved in pedagogy and literacy is taken up and whether it is possible with this labelling to attend to moving with another. For example, in early childhood, a considerable part of practice involves giving children words to identify objects or movements to properly express themselves. This is often self-focused and is described, for example, in documents such as the MOVERS document, a prescriptive moving practice document which identifies language acquisition as a way to "broaden physical literacy" (Archer, Siraj \& Okley, 2017, p. 10). As a move away from this human-centered linguistic labelling 
practice, Ingold's (2011) meshwork is rooted in inverting inversive logics or exploring worlding practices in movement rather than through cognitive analysis or identification. He asks "does all meaning, and value lie in systems of significant symbols? If so, then the motives and finalities for human action on the environment must lie with what the mind brings to it: in ideas, concepts and categories of a received cultural tradition" (p. 76). This means that tracking the names of mushrooms, is an exercise of culture, enacting a culture of categorization that that draws upon our rationalist ways of thinking and knowing. Moving with mushroom, I propose, may require a different attendance with it that moves beyond labelling.

With the children in the moment of getting to know the mushroom that I have been returning to, I drew on a simple and general categorization: the mushroom. This categorization already came with pre-established knowledges, cultures and perhaps moralizations of what I had hoped we would think about in the playground. However, I am reminded of John Law and Marien Lien's (2018) fieldwork with salmon where they

cultivated the principle of naïve observation, assuming that we [they] did not know beforehand what a salmon is, and paid particular attention to the heterogenous networks and relational practices that make up the realities that are often otherwise taken for granted by coworkers and fieldworks alike. (p. 159)

Perhaps a question of watching worlding practices rather than observing the mushroom through pre-determined normative naming or labelling of could encourage this kind of noticing. For example, what if we take muscles tensing, giving off heat, extending to the crunch of/in these entanglements that are poking outside of the log as ways of attuning to our relational worlds with 
mushrooms? Otherwise and additionally, noticing could be in the slow movements that shape and change growth.

\section{Slowing down to 'communicate'}

If we take my initial question or proposition of communication as movement in mind, tracking mushroom communication cannot be a fast-track or categorical process. Perhaps it would be useful to think about this attention through modest witnessing (Haraway, 1997; Rose, 2015) growths of movement and paths of movement that are "active, engaging and connected to response-ability" (Blaise, Hamm \& Iorio, 2017, p. 35). I think of this as a reimagination of connection and an establishment that we cannot 'know' the other, or even the relation with the other cognitively but can engage in slow and consequential moving (Land \& Danis, 2016) withother. In this case, mushrooms are encouraging a slowing down, or perhaps to engage in a slow kind of pedagogy that Tonya Rooney (2019) offers as a response to her concerns of climate change and how rapidly we move through place. For Rooney, to slow down is practice of noticing the messy, complex entanglements of past, present, and future that mark our times. In response to our constant need to categorize, own, and solve the problem of mushrooms, slowing down would mean spending time with movements we can perceive, and movements that are not

perceivable. I am reminded of the frustration we experienced as educators, when the mushrooms continuously came up into the playground, regardless of the labour involved in exterminating them. Would slowing down mean letting the mushrooms grow, in a slow attendance or witness of how they move? How might this come into tension with the removal of (what we are taught to see as) the problem? How might the unknown growths, or the fact that unknowable growth is a possibility, allow us to tune to worlds that are not engaged in quick problem solving? 
I think that these frustrating, loopful thoughts stop me to stay in trouble slowly with what Isabelle Stengers (2013) discusses as a caring for entanglements in response to urgent goaloriented forms of action. For Stengers, "goal-oriented action can convey a sense that things which 'inspire hesitations or attention must be banished' leaving potentially significant matters lying unnoticed" (Stengers, 2013, p. 179 as cited in Rooney, 2019, p. 180). Playing with these ideas is head-spinning and perhaps that is the point in worlding practices. We cannot cognitively or categorically establish communication or relationship with more than human worlds through notions perceivable to humans - or rather, particular humans. Categorizations are a humanist creation and are not objective truths. A slowing down with the mushrooms and children, and even questions that we form together, can allude to this practice, as slow changes might alert us to entanglements that reveal other possibilities to be with the mycelium that grows throughout the playground.

\section{Entrance in Symbiosis and Non-symbiosis, Commons and Un-commons}

So too, the lifelines of organisms issue from the sites of their symbiotic connection, but in a direction that runs not from one to the other but forever in between, as the river flows between its banks in a direction orthogonal to their transverse connection (Ingold, 2011, p. 83)

I am jumping now to another event that is connected and disconnected to my thinking about mycelium with the children. As mentioned earlier, our inquiry started with what it means to move with logs that were cut from trees deemed to be invasive (logs cut from 'invasive' trees growing down the street - another baddie, as Taylor (2017) would argue humanist moralizing 
logics might have us think. On these logs, we witnessed mushroom growths and wondered about what mushroom communication can mean in relation with a meshworked playground. Thinking with Ingold (2011) and with the entanglements of mushroom networks, the solitary mushroom is not bound to the individual log. If we are to look at the playground as an endless or boundless meshwork then we can jump to questions such as "What lies in mushroom/log/centipede/slug/child relations?" This question is endless in complexity. During my initial mushroom conversation with the children, I discussed how the trees change the mushrooms and the mushrooms change the trees. This is beautifully described by Anna Tsing (2010) as she discusses the multiplicity of relationships that mushrooms may have from the redistribution of sugars from tree to tree to the decomposition of rocks, trees, and other life forms. It is in this decomposition that perhaps some of the animals, for example potato bugs and the slugs and ch-worms in the story below, share some relation with fungi. What if, in our movements of moving and jumping off the logs, or our endless lines of flight, we are moving with complex meshworks of decomposing relations? 


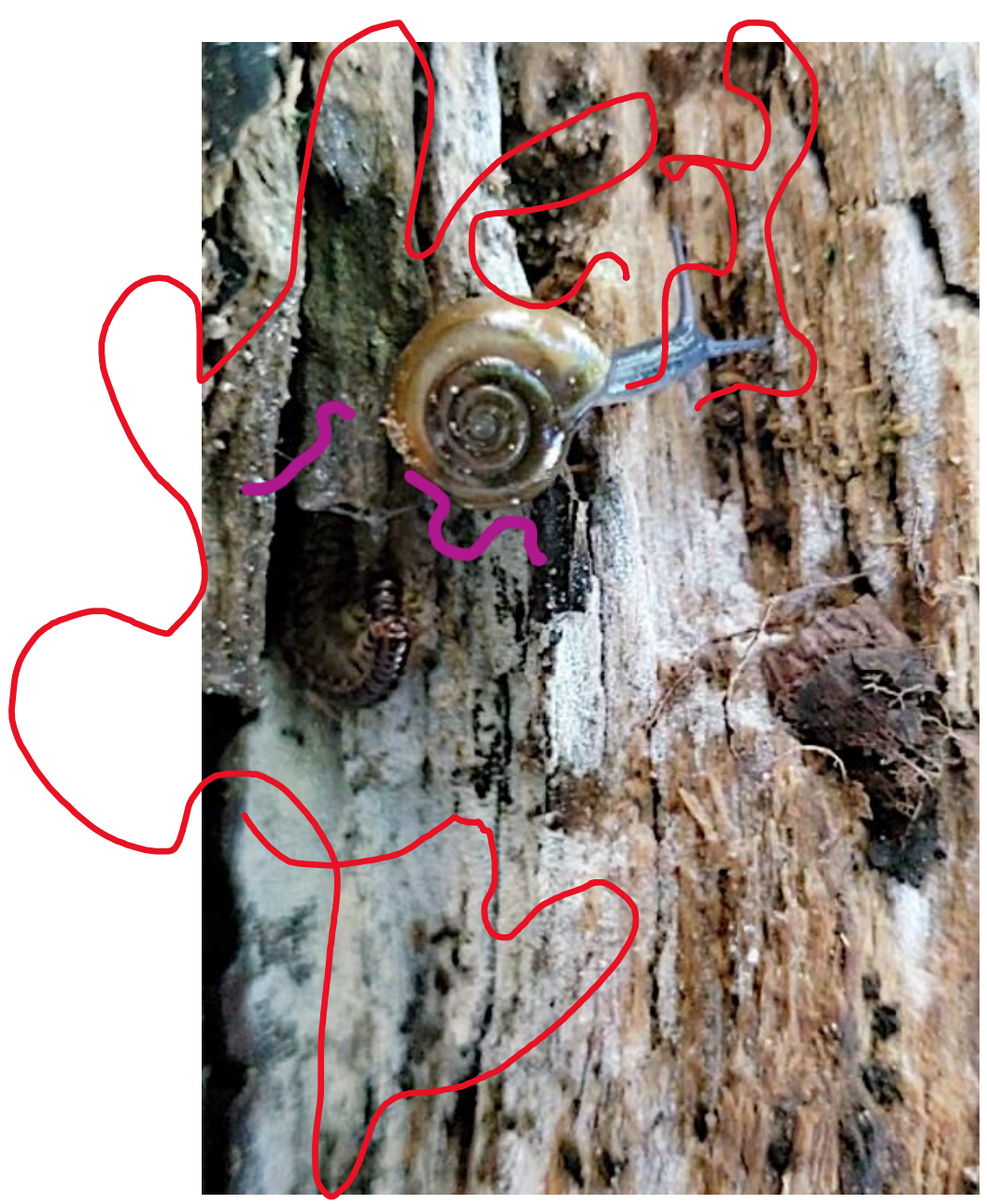

Figure 3.2. The snail and the ch-worm.

With the children, we spent a while thinking with the critters in the decomposing logs. The children were fascinated by the critters' movements and their lack of movements. This particular photo, in Figure 3.2, was taken after many weeks of searching for insects. As the children and I sat together with the logs, a question arose: "Why is not moving?" I wondered how to respond, "I think it's moving very slowly, maybe like a tiny micromovement." I thought of Erin Manning's (2014) description of micromovements, in vibrations, leg twitches, that contribute thousands of rebalancings. Similarly, the slug is engaging in its own micromovement as it moves along lines, meshed in and knotted with other species and the decaying log. The slug slowly slugged as we slowly dropped our knees to the ground and our postures attempted to stay 
out of the way of the slug's periphery. After some time, we noticed another insect behind the slug: "Look the ch-worm is there, beside him, why?" Someone responded, "Because it's protecting the ch-worm because, they're friends".

\section{Moving Along the Line of Distaste-ful Relation-ship.}

An article titled, Mushrooms Fight Back in Natural Life (Life Media, 2001) opened with the statement, "there are many kids who find mushrooms distasteful. Apparently, slugs feel the same way" (para. 1). According to this article rooted in scientific knowledges, when slugs bite mushrooms, the mushrooms release distasteful chemicals. Connecting to the playground and getting to know the slug, maybe, and this is a presumption, these slugs here are also not necessarily too fond of the hovering mushrooms on the rotten logs in the playground - but they are certainly getting cozy with the "ch-worms" (as one child described in the story above) and with the decaying log. This idea of the slug as a protector to the ch-worm, as the child proposed, can be taken up in so many ways. Perhaps it is an expression of the concern we see in species relations and in early childhood nature discourse where concern is manifested in friendship and saviorisms or heroic solution finders (Haraway, 2008, 2015; Taylor, 2013) . I would like to add that I am not quite sure if the "ch-worm" was indeed 'alive' or moving. Stories of friendship, like this narrative, have non-innocent implications in relation to the romanticized way in which the nature-child binary is taken up or in the current fun context of early childhood education. Vintimilla (2014) discusses neoliberal fun as an innocent way in which experiences are generalized to avoid uncomfortable conflicts in early childhood. This type of generalization of fun is inherent in the managing of child and educator subjectivities in line with innocent and romanticized images of childhood. I propose that in this case, fun is also entangled in friendship and relation-ship of the slug-mushroom-ch-worm-log relation. I want to move back to the 
distaste-ful friendship posited by scientific research between the slug and the mushroom. Moving through the playground's meshworks while attending to more-than-human movements is more complex than friendship and may indeed be distasteful. Fungi drain sugars, give sugars, release foul tastes, and ch-worms and slugs might not be friends. Feet interrupt insect movements, while hands may contribute to the destruction of fruiting mycelium. And even in symbiotic relations, I am called to think with common (un)commons. Blazer and Cadena (2017) state:

symbiosis means that these beings are related by common interests, but common does not mean having the same interest in common, only that diverging interests now need each other. Symbiotic events are a matter of opportunity, of partial connection, not of harmony. (p. 7)

And it is with these unharmonious entanglements, that perhaps I can consider moving through the meshwork. Being in a common world would require we redefine what it means to be 'social'. Looking at the entanglements of the slug, fungi, human, not as sovereign bodies but as minifragments, perhaps in tension with each other, never connected together but knotted together draws my attention to the uneasiness in relationship that is needed to respond to the anthropocentric time in which we are currently entangled with. We are all in (dis)taste-ful relation, knotted together in an urgency to respond to the entangled destructions of our common and uncommon worlds.

\section{Final Thoughts}

Thinking with moving through a meshwork, alongside responding to our current anthropocentric, destructive times, I have thought with two moments from a pedagogical inquiry 
research project to unsettle the bounded individual by thinking with moments of moving with that engaged in boundary crossings. I traced how thinking with moving requires of us a different kind of noticing within (un)common/common worlds that works to respond to human-centered ways we engage with species of least concern, like logs and rats and mushrooms. I complexified the presumed hierarchical positions of human language and cognitive representations, wondering how we might be with more-than-human others who communicate in ways imperceptible to humans. As the meshwork is always in continuous becoming, identifications, I argued, are not enough as we follow how we are implicated in the playground. Donna Haraway's (2016) storytelling describes "fabulations and speculative realisms" (p. 10) where "multispecies players who are enmeshed in partial and flawed translations across difference, redo ways of living and dying attuned to still possible finite flourishing [and] still possible recuperation" (p. 10). I want to propose that visiting the playground as a meshwork creates these moments of possibility for speculation and fabulation. However, I would like to also take seriously Anna Tsing's (2010) proposition of naming to notice and present this tension as a provocation to think with movement, goodies and baddies, commons and un-commons, in a tension that is not necessarily tasteful but is necessary. What does it mean to think of relationship as distasteful, messy and not completely knowable in early childhood education? How do we understand relationships with more than human species beyond human perception and its reliance on knowable objective futures? 


\section{Appendix A: Letter to Parents}

Ryerson

University

\section{Parent/Family Letter of Information and Consent Form Activating pedagogies to support children's movement in early childhood education}

Your child is being invited to participate in a research study. Please read this consent form so that you understand what their participation will involve. Before you consent for your child to participate, please ask any questions to be sure you understand what participation will involve.

This research is being conducted by Dr. Nicole Land from the School of Early Childhood Studies at Ryerson University. Some early childhood educators from the Ryerson Early Learning Centre will be co-researchers.

This study is funded by a Ryerson Faculty of Community Services Seed Grant.

If you have any questions or concerns about the research, please contact Nicole Land at nland@ryerson.ca or 416-979-5000 ext. 7538.

\section{Purpose of this Research Project}

This research project will explore how children and early childhood educators at the Ryerson Early Learning Centre understand movement in their everyday activities. This is an educatoraction research project, which means that educators will take on a co-researcher role. Together with the researcher, educators will collectively design research questions and activities, create and analyze data, and share our findings. This research uses a pedagogical inquiry methodology, which means that we inquire together with children into how teaching practices respond to and influence children's experiences of movement.

Your child is being asked to participate in this study because they attend the Ryerson Early Learning Centre. At least one of the educators in your child's classroom is participating in the research as a co-researcher.

In addition to other ways we will share our findings, Alicja Frankowski, an educator coresearcher from the Early Learning Centre, will utilize some of our data in a Master's Research Paper as a degree requirement for a Master of Arts in Early Childhood Studies.

\section{What Your Participation Means}

If you volunteer for your child to participate in this study, they will be involved in learning experiences related to movement that are co-created by educator co-researchers (who are your children's teachers) and Nicole. The research will continue until December 2019 and will take place during the everyday activities your child is already part of in the ELC. All children will be invited to participate in learning experiences as they will be integrated into the classroom environment. Learning experiences do not 'teach' about movement nor 'assess' movement but 
are concerned with investigating movement together. Data will be collected only for children who have consent to participate in the research.

Together with children, the researcher and educator co-researchers will: identify specific questions that we have about movement, create invitations or experiences (activities, lessons, questions, and conversations) to extend our understanding of movement, consider how the inquiry informs our practices and curriculum, and revisit questions and learning experiences to continually offer opportunities for learning with moving that respond to the insights we gain in our research. Children and researchers will work collaboratively to develop, engage with, and document learning experiences, and researchers will often share data and ideas with children to incorporate children's voices and understandings. We will offer weekly 2-hour learning experiences that will happen concurrent to other classroom activities. Children will always have the option to participate or decline to participate in the research inquiry work. Educator coresearchers and Nicole will actively participate in these activities with children, as we work through the learning experience together and support children's learning and inquiry.

During these learning experiences, researchers will create data (photographs, video, voice notes, field notes, writing, blog posts) by documenting ordinary moments and the learning experiences we offer. Children's creations (crafts, drawings) and quotes from children may also be included as data. We will always check in with your child to ensure they know how and what we are documenting, and children will have opportunities to review documentation and the reflections/analysis created by educator co-researchers and Nicole. We respect children's ability to decline to be in photographs, video, or field notes and will confirm with children before their creations or quotes are shared publicly beyond the research team. Educator co-researchers will participate in large and small group meetings, as well as writing and critical reflection.

It is very important to note that this research is never about evaluating the quality of any educators' work or the learning of specific children in the classroom. Your child's movement skills or capabilities are not the focus of this research. Rather, we are investigating how our teaching practices influence children's movement.

Our findings, including our data (photographs, video, field notes, writing, blog posts), may be shared in multiple ways. These include:

- Journal articles or book chapters

- Conference presentations

- Professional ECE publications

- Master's Research Paper (as a degree requirement for a Master of Arts in Early Childhood Studies) by Alicja Frankowski

- Sharing documentation within the classroom with children and families

- Sharing documentation more publicly with the community (hallways, exhibits)

- Online pedagogical conversations

No images of children's faces will be utilized in online activities. Images will only include non-identifiable features and, whenever possible, will not include children. Utilizing online practices to share our inquiries allows us to contribute to international digital conversations about innovative ECE pedagogies. This is vital for building a 
network of fast-moving knowledge related to pedagogy and is already a vibrant channel for knowledge mobilization in early childhood studies.

○ Research websites (for example: https://www.earlychildhoodcollaboratory.net)

- Blogs on Ryerson's Wordpress Multisite (for an example of pedagogical inquiry research blogs, please see: http://www.climateactionchildhood.net)

- Twitter (for an example of educator co-researchers utilizing Twitter to share findings, please see: https://twitter.com/common_worlds)

\section{Potential Benefits}

Children potentially benefit through opportunities to co-create and participate in unique, responsive, co-created everyday pedagogical inquiry activities and learning experiences. Through our emphasis on developing locally-meaningful pedagogies to promote children's movement, this research can potentially benefit society by deepening our understanding of how and why children move, and how and why educators might shape children's relationships with movement. This research might benefit the early childhood education field in Ontario by providing evidence-based examples of how educators integrate multiple forms of knowledge and meaning-making within their critically reflective everyday practice.

I cannot guarantee, however, that your child will receive any benefits from participating in the study.

\section{Potential Risks}

There are minimal risks associated with your child's participation in this research. Children, especially in images, might be identifiable to those who know them already. In our research dissemination materials, we will never refer to the ELC by name. Educator co-researchers who do not wish to be identified and all children will be assigned pseudonyms.

\section{Confidentiality}

Your child's confidentiality will be maintained by ensuring that children's names are never used in research dissemination materials nor in the storage of research data. No one beyond the research group (research and educator co-researchers) will have access to our data and research materials.

We will protect your child's confidentiality by referring to children by pseudonyms and never naming the Early Learning Centre directly in publication materials. Please note that educator coresearchers in the project or community members who already know your child will be able to recognize your child in images.

All data production, collection, and storage activities will follow any policies already in place at the Early Learning Centre. Data will be stored on a secure Ryerson Google Drive that is accessible only to the research team. Hard copy data (consent forms, printed artefacts) will be stored in a locked file cabinet in the researcher's office, KHS 363P. Educator co-researchers will often share data with children for their review. If we are documenting an image, quote, or artefact made by a specific child, we will always check in with that child. 
All data will be stored for 6 years. Digital files will then be destroyed and hard-copy data will be shredded.

\section{Voluntary Participation and Withdrawal}

Your child's participation in this study must be entirely voluntary. Choosing to participate or not participate does not impact your child's enrolment or learning at the Early Learning Centre, nor your relationship with the researcher, School of Early Childhood Studies, or Ryerson University. If you feel influenced to participate due to any pre-existing relationships, you should decline for your child to participate.

We will continually check in with your child about their participation. Children will always have the option to participate or not participate in learning experiences, as they will be offered as part of the programming of the classroom and children will be able to move from activities as they usually do. We will have ongoing conversations with children about movement, the research, and our data. If children identify specific pieces of data that they prefer not to be included as data, that data will be excluded.

If you do decide for your child to participate, you can withdraw at any time. If you choose for your child to stop participating, their data will not be included in the research. In this case, we will not include any documentation they created or that contains your child's image/words/contributions.

\section{Questions about the Research}

If you have any questions about the research now, please ask. If you have questions later about the research, please contact Nicole Land at nland@ryerson.ca or 416-979-5000 ext. 7538.

This study has been reviewed by the Ryerson University Research Ethics Board (REB file number 2018-457). If you have questions regarding your rights as a participant in this study, please contact the Research Ethics Board at rebchair@ryerson.ca or 416-979-5042. 


\section{Confirmation of Agreement \\ Activating pedagogies to support children's movement in early childhood education}

Your signature below indicates that you have read the information in this agreement and have had a chance to ask any questions you have about the study. Your signature also indicates that you agree for your child to participate in the study and have been told that you can change your mind and withdraw your consent to participate at any time. You have been given a copy of this agreement. You have been told that by signing this consent agreement you are not giving up any of your legal rights.

\section{Name of Child}

(Please print)

\section{Name of Parent/Guardian}

(Please print)

Signature of Parent

Date

I agree for my child to be included in photographs and audio or video recordings for the purposes of this study. I understand how these recordings will be stored and destroyed.

Signature of Parent/Guardian 


\section{Appendix B- Letter to Educators}

\section{Ryerson}

University

\section{Educator Co-Researcher Letter of Information and Consent Form Activating pedagogies to support children's movement in early childhood education}

You are being invited to participate in a research study. Please read this consent form so that you understand what your participation will involve. Before you consent to participate, please ask any questions to be sure you understand what your participation will involve.

This research is being conducted by Dr. Nicole Land from the School of Early Childhood Studies at Ryerson University. Some early childhood educators from the Ryerson Early Learning Centre will be co-researchers.

This study is funded by a Ryerson Faculty of Community Services Seed Grant.

If you have any questions or concerns about the research, please contact Nicole Land at nland@ ryerson.ca or 416-979-5000 ext. 7538.

\section{Purpose of this Research Project}

This research project will explore how children and early childhood educators (ECEs) at the Ryerson Early Learning Centre understand movement in their everyday activities. This is an educator-action research project, which means that you, as an educator, will take on coresearcher role as we collectively design research questions and activities, create and analyze data, and share our findings. We use a pedagogical inquiry methodology, which means that our research is about inquiring together with children into how your teaching practices respond to and influence children's experiences of movement.

You are being asked to participate in this study because you are an early childhood educator at the Ryerson Early Learning Centre. Children who attend your program will be invited to participate in this research as well.

In addition to multiple knowledge mobilization activities that we will use to share our findings, Alicja Frankowski, an educator co-researcher from the Early Learning Centre, will utilize some of our data in a Master's Research Paper as a degree requirement for a Master of Arts in Early Childhood Studies.

\section{What Your Participation Means}

If you volunteer to participate in this study, you will be asked to be an educator co-researcher. This means that, over the course of the next 9 months (ending in December 2019), you will conduct pedagogical inquiry research, alongside the researcher, in your classroom. Pedagogical inquiry activities align with the work you already do as an educator: identifying specific 
questions that educators and children have about movement, creating invitations or experiences to extend our understanding of movement, considering how the inquiry informs your pedagogical practices, and revisiting and re-imagining questions and learning experiences with children to continually offer opportunities for learning with moving that respond to the insights we gain in our research. You may choose to incorporate ideas generated within our research into your daily practices.

As a co-researcher, you will collaborate with the PI and other ECE co-researchers to co-create weekly inquiry-based learning experiences for children. Together, we will share and participate in these activities with children during your program. Throughout these experiences, you will create data (images, video, audio, field notes, writing, blog posts) and will contribute to conversations with children and co-researchers related to this documentation. You, and the researcher and co-researchers, will document ordinary moments and the learning experiences we offer using photographs, video, audio, and written reflections. Together, and individually, we will the reflect on this documentation. We will share our reflections or emerging findings within our research team in printed and digital documents, on a blog, and during research meetings.

You will also participate in small and large group research meetings with the researcher and coresearchers, where we will discuss readings, ideas, and documentation. We will have conversations about the moments that we have documented. These conversations are collaborative and are intended to help us to revisit and re-design learning experiences. We will think with questions like "how is learning happening in this moment?" and "how can we support children to learn differently in this experience?". You will have 3 hours each month of off-thefloor time to read, write, and work with documentation. Research meetings and release time will occur during your working hours and the research project will cover the cost of supply teachers. Small group meetings will occur weekly (30 - 60 minutes; $1-3$ educator co-researchers and the PI) and large group meetings will occur monthly (60 minutes; all educator co-researchers and the PI). We will work together to determine a schedule that works for you and your classroom. You might or might not choose to dedicate additional time to your work as a co-researcher. If so, you will determine the amount of time beyond work hours that you devote to the project.

It is very important to note that this research is never about assessing or evaluating the quality of your work or the learning of specific children in your classroom.

Our findings and documentation (photographs, video, field notes, writing, blog posts), may be shared in multiple ways. As a co-researcher, you will participate in selected dissemination activities as you choose:

- Journal articles or book chapters (co-authoring, writing individually)

- Conference presentations

- Professional ECE publications

- Sharing documentation within your classroom

$\circ$ You might choose to communicate research activities to families via practices already in place in your classroom

- Sharing documentation more publicly with the community (hallways, exhibits)

- Online pedagogical conversations

No images of children's faces will be utilized in online activities. Images will only 
include non-identifiable features and, whenever possible, will not include children. Utilizing online practices to share our inquiries allows us to contribute to international digital conversations about innovative ECE pedagogies. This is vital for building a network of fast-moving knowledge related to pedagogy and is already a vibrant channel for knowledge mobilization in early childhood studies.

○ Research websites (for example: https://www.earlychildhoodcollaboratory.net)

- Blogs on Ryerson's Wordpress Multisite (for an example of pedagogical inquiry research blogs, please see: http://www.climateactionchildhood.net)

- We will begin with a private (hidden) blog, accessed only by coresearchers via their Ryerson account. We will use this to share our thinking internally. In the spring, we will develop a public blog to begin disseminating our findings.

- Twitter (for an example of educator co-researchers utilizing Twitter to share findings, please see: https://twitter.com/common_worlds)

The research will also be used within a Master's Research Paper (as a degree requirement for a Master of Arts in Early Childhood Studies) by Alicja Frankowski.

\section{Potential Benefits}

As an educator co-researcher, you will potentially benefit by participating in practice-based and critically reflective pedagogical inquiry research. This is an opportunity to build your research capacity and to make a contribution toward creating pedagogies to support children's movement. Through our emphasis on developing locally-meaningful pedagogies to promote children's movement, this research can potentially benefit society by deepening our understanding of how and why children move, and how and why educators might shape children's relationships with movement. By focusing explicitly on weaving existing physical education pedagogies with How Does Learning Happen, this research might benefit the ECE field in Ontario by providing evidence-based examples of how educators integrate multiple forms of knowledge and meaningmaking within their critically reflective everyday practice.

I cannot guarantee, however, that you will receive any benefits from participating in the study.

\section{Potential Risks}

There are minimal risks associated with your participation in this research. Sometimes pedagogical conversations with co-researchers can be difficult; we might not always agree on our interpretations or our ideas. This means that there is a possibility that you might feel uncomfortable or upset during research meetings. You are able to leave at any time. We will continually revisit our commitment to doing good pedagogical work together in an effort to ensure that we are collaborating well. You will be given the opportunity to waive your confidentiality in research dissemination materials, which means your personal identity will then be revealed. It is your choice if you wish to waive your confidentiality. In our research dissemination materials, we will never refer to the ELC by name. Educator co-researchers who do not wish to be identified and all children will be assigned pseudonyms.

\section{Confidentiality}


While we will have practices to maintain confidentiality, confidentiality cannot be guaranteed given the group nature of the study.

Your confidentiality, and the confidentiality of the data we create, will be maintained by ensuring that no one beyond the research group has access to our data and research materials. As a co-researcher, you will know which colleagues and children have consented to participate in the research. You must keep this confidential by not discussing this with people who are not in the research.

We will protect your confidentiality by referring to co-researchers by pseudonyms and never naming the Early Learning Centre directly in publication materials. We will extend this same practice to children who participate. Please note that other educators involved in the project, or colleagues you already know in the field, will be able to recognize you. Community members and families may also recognize you in research materials. Please do not reveal discussions or data with people who are not participating in the research.

As an educator co-researcher, you can decide to waive confidentiality. This allows for your contributions to be associated with your name and professional identity (such as in co-authoring) should you wish.

As a co-researcher, you will have access to our shared data. All data production, collection, and storage activities must follow any policies already in place at the Early Learning Centre. Data will be stored on a secure Ryerson Google Drive, which you will have access to via your Ryerson matrix log in. Hard copy data (consent forms, printed artefacts) will be stored in a locked file cabinet in the researcher's office, KHS 363P. You will be able to review all data you create, and you can choose to not include certain pieces of writing/reflection as data. You might also have access to printed data (writing, photographs, field notes). You should treat these in accordance with the Early Learning Centre's guidelines for privacy and data storage. It is expected that you will maintain the assurances of confidentiality made to other co-researchers and to parents/families and children in all research and dissemination activities. We will discuss this during our first research meeting.

All data will be stored for 6 years. Digital files will then be destroyed and hard-copy data will be shredded.

\section{Incentives for Participation}

You will not be paid to participate in this research study.

You will receive, via the Early Learning Centre, some off-the-floor time to be a co-researcher. The project will cover the costs of supply teachers for 3 hours each month for each coresearcher. This is to allow you time during your workday to participate in research activities that go beyond the learning experiences we will engage with together with children.

\section{Voluntary Participation and Withdrawal}

Your participation in this study must be entirely voluntary. Choosing to participate or not participate does not impact your employment or relationship with the researcher, School of Early 
Childhood Studies, or Ryerson University. If you feel influenced to participate due to any incentives or pre-existing relationships, you should decline to participate. As a co-researcher, we will determine together the exact activities you participate in. You might, for example, prefer to share documentation in printed form instead of the blog. You might choose to participate in some dissemination activities and not others. This might change over the course of the research. You take the lead in determining exactly what your participation entails.

If you do decide to participate, you can withdraw at any time. If you choose to stop participating, your data will not be included in the research. In this case, we will not include any documentation you created or that contains your image/words/contributions.

\section{Questions about the Research}

If you have any questions about the research now, please ask. If you have questions later about the research, please contact Nicole Land at nland@ ryerson.ca or 416-979-5000 ext. 7538.

This study has been reviewed by the Ryerson University Research Ethics Board (REB file number 2018-457). If you have questions regarding your rights as a participant in this study, please contact the Research Ethics Board at rebchair@ryerson.ca or 416-979-5042. 


\section{Confirmation of Agreement \\ Activating pedagogies to support children's movement in early childhood education}

Your signature below indicates that you have read the information in this agreement and have had a chance to ask any questions you have about the study. Your signature also indicates that you agree to participate in the study and have been told that you can change your mind and withdraw your consent to participate at any time. You have been given a copy of this agreement. You have been told that by signing this consent agreement you are not giving up any of your legal rights.

Name of Participant

(Please print)
Signature of Participant

Date

I agree to be included in photographs and audio or video recordings for the purposes of this study. I understand how these recordings will be stored and destroyed.

Signature of Participant

I choose to waive my confidentiality. I would like to be identified by name in any dissemination activities.

Signature of Participant 
Appendix C- REB Approval

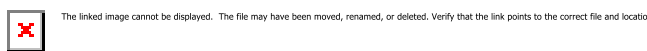


References for the Introduction

Aboriginal Education Council (2010). Egerton Ryerson, the residential school system and truth and reconciliation. Retrieved from https://www.ryerson.ca/content/dam/aec/pdfs/egerton\%20ryerson_fullstatement.pdf Aboriginal Education Council (2019). Ryerson land acknowledgement. Retrieved from https://www.ryerson.ca/aec/land-acknowledgement/

Allen-Collinson, J., \& Owton, H. (2015). Intense embodiment: Senses of heat in women's running and boxing. Body \& Society, 21(2), 245-268. doi:10.1177/1357034X14538849

Barad, K. M. (2007). Meeting the universe halfway: Quantum physics and the entanglement of matter and meaning. Durham, NC: Duke University Press.

Blaser, M., \& de la Cadena, M. (2017). The uncommons: An introduction. Anthropologica, 59(2), 185-193. doi:10.3138/anth.59.2.t01

Cadena, M. \& Blaser, M. (2018). A world of many worlds. Durham, NC: Duke University Press.

Clark, V., Pacini-Ketchabaw, V., \& Hodgins, B. D. (2014). Thinking with paint: troubling settler colonialisms through early childhood art pedagogies. International Journal of Child, Youth \& Family Studies, 5(4), 751-781.

Cole, P. (2002). land and language: translating aboriginal cultures. Canadian Journal of Environmental Education, 7(1), 67-85.

Common Worlds Research Collective (2019). About the Collective. Retrieved from http://commonworlds.net/about-the-collective/

Culp, B. (2017). "Illegitimate" bodies in legitimate times: Life, liberty, and the pursuit of movement: National association for kinesiology in higher education 26th delphine hanna commemorative lecture 2017. Quest, 69(2), 143-156. 
doi:10.1080/00336297.2017.1287578

Hackett, A. (2016). Young children as wayfarers: Learning about place by moving through it. Children \& Society, 30(3), 169-179.

Haraway, D. (2016). Staying with the trouble: Making kin in the Cthulucene. London, UK: Duke University Press.

Hodgins, B. D. (2019). Introduction: Common worlding research. In B. D. Hodgins (Ed.), Feminist research for 21 st-century childhoods: Common worlds methods (pp. 124). London, UK: Bloomsbury.

Larsson, H., \& Quennerstedt, M. (2012). Understanding movement: A sociocultural approach to exploring moving humans. Quest, 64(4), 281-298. doi:10.1080/00336297.2012.706884

Ingold, T. (2011). Being alive: Essays on movement, knowledge and description. London, UK: Routledge. doi:10.4324/9780203818336

Land, N., \& Ildikó Danis. (2016). Movement/ing provocations in early childhood education. Canadian Children, 41(3), 26-37.

Moving Pedagogies Blog (2019). Moving pedagogies. Retrieved from https://movingpedagogies.blog.ryerson.ca

Moss, P. (2010). We cannot continue as we are: The educator in an education for survival. Contemporary Issues in Early Childhood, 11(1), 8-19. doi:10.2304/ciec.2010.11.1.8

Moss, P. (2016). Why can't we get beyond quality? Contemporary Issues in Early Childhood, 17(1), 8-15. doi:10.1177/1463949115627895

Pacini-Ketchabaw, V., Kummen, K., \& Thompson, D. (2010). Becoming intimate with developmental knowledge: Pedagogical explorations with collective biography. Alberta Journal of Educational Research, 56(3), 335-354. 
Rautio, P. (2013). Children who carry stones in their pockets: On autotelic material practices in everyday life. Children's Geographies, 11(4), 394-408.

doi:10.1080/14733285.2013.812278

Rautio, P. (2017). Thinking about life and species lines with pietari and otto (and garlic breath). TRACE $\therefore$ Journal for Human-Animal Studies, 3, 94-102. Retrieved from https://trace.journal.fi/article/view/63310

St. Pierre, E. A. (2000). Poststructural feminism in education: An overview. International Journal of Qualitative Studies in Education, 13(5), 477-515. doi:10.1080/0951839005015642

Sutton-Smith, B. (1997). The ambiguity of play. Cambridge, MA: Harvard.

Taylor, A. (2017). Beyond stewardship: Common world pedagogies for the anthropocene. Environmental Education Research, 23(10), 1448-1461. doi:10.1080/13504622.2017.1325452

Tsing, A. L. (2015). The mushroom at the end of the world: On the possibility of life in capitalist ruins. Princeton, US: Princeton University Press.

Tuck, E., \& Yang, K.W. (2012). Decolonization is not a metaphor. Decolonization: Indigeneity, Education \& Society, 1(1), 1-40.

Vintimilla, C. D. (2018). Encounters with a pedagogista. Contemporary Issues in Early Childhood, 19(1), 20-30. doi:10.1177/1463949116684886

Woodyer, T. 2008. The body as research tool: Embodied practice and children's geographies. Children's Geographies 6 (4): 349-362. 


\section{References for Article 1}

Aboriginal Education Council (2010). Egerton Ryerson, the Residential School System and Truth and Reconciliation. Retrieved from https://www.ryerson.ca/content/dam/aec/pdfs/egerton\%20ryerson_fullstatement.pdf Aboriginal Education Council (2019). Ryerson land acknowledgement. Retrieved from https://www.ryerson.ca/aec/land-acknowledgement/

Azzarito, L. (2009). The panopticon of physical education: Pretty, active and ideally white. Physical Education and Sport Pedagogy, 14(1), 19-39. doi:10.1080/17408980701712106

Barad, K. M. (2007). Meeting the universe halfway: Quantum physics and the entanglement of matter and meaning. Durham, NC: Duke University Press.

Blaise, M., Hamm, C., \& Iorio, J. M. (2017). Modest witness(ing) and lively stories: Paying attention to matters of concern in early childhood. Pedagogy, Culture \& Society, 25(1), 31-42. doi:10.1080/14681366.2016.1208265

Blaser, M., \& Cadena, M. (2017). The uncommons: An introduction. Anthropologica, 59(2), 185-193. doi:10.3138/anth.59.2.t01

Cadena, M. \& Blaser, M. (2018). A world of many worlds. Durham, NC: Duke University Press.

Clark, V., Pacini-Ketchabaw, V., \& Hodgins, B. D. (2014). Thinking with paint: troubling settler colonialisms through early childhood art pedagogies. International Journal of Child, Youth \& Family Studies, 5(4), 751-781. 
Colebrook, C. (2014). Death of the posthuman: Essays on extinction, Vol. 1. Michigan, US: Open Humanities Press. doi:10.3998/ohp.12329363.0001.001

Culp, B. (2017). "Illegitimate" bodies in legitimate times: Life, liberty, and the pursuit of movement: National association for kinesiology in higher education 26th Delphine Hanna commemorative lecture 2017. Quest, 69(2), 143-156.

doi:10.1080/00336297.2017.1287578

Dahlberg, G., \& Moss, P. (2004). Ethics and politics in early childhood education. Abington, Oxfordshire: Routledge Falmer.

Dahlberg, G. \& Moss, P. (2018) Reconceptualising evaluation in early childhood education. In Bloch, M.N, Swadener B. B. \& Cannella G.S. (Eds..), Reconceptualizing early childhood education and Care- A READER (pp. 2741-3319). New York, NY: Peter Lang.

Edwards, E. (2012). Objects of affect: Photography beyond the image. Annual Review of Anthropology, 41, 221-234. doi:10.1146/annurev-anthro-092611-145708

Gibson, K., Rose, D. B., \& Fincher, R. (2015). Manifesto for living in the anthropocene. Brooklyn, NY: Punctum books. doi:10.21983/P3.0100.1.00

Haraway, D. (2008) When Species Meet. Minneapolis, MN: University of Minnesota Press. Haraway, D. (2016). Staying with the trouble: Making kin in the Cthulucene. London, UK: Duke University Press.

Hultman, K., Lenz Taguchi, H. (2010). Challenging anthropocentric analysis of visual data: A relational materialist methodological approach to educational research. International Journal of Qualitative Studies in Education, 23(5), 525-542.

doi:10.1080/09518398.2010.50062 
Ingold, T. (2011). Being alive: Essays on movement, knowledge and description. London, UK: Routledge. doi:10.4324/97802038183

Invading Species Awareness Program (2019). Emerald Ash Borer. Retrieved from http://www.invadingspecies.com/emerald-ash-borer/

Kind, S. (2013). Lively entanglements: The doings, movements and enactments of photography. Global Studies of Childhood, 3(4), 427-441. doi: dx.doi.org/10.2304/gsch.2013.4.27

Land, N., \& Danis. I. (2016). Movement/ing provocations in early childhood education. Canadian Children, 41(3), 26-37.

Larsson, H., \& Quennerstedt, M. (2012). Understanding movement: A sociocultural approach to exploring moving humans. Quest, 64(4), 281-298. doi: 10.1080/00336297.2012.706884

Latour, B. (2004). Why has critique run out of steam? from matters of fact to matters of concern. Critical Inquiry, 30(2), 225-248. doi:10.1086/421123

Malone, K. (2016). Reconsidering children's encounters with nature and place using posthumanism. Australian Journal of Environmental Education, 32(1), 42-56. doi:10.1017/aee.2015.48

Markula, P., \& Pringle, R. (2007). Foucault, sport and exercise: Power, knowledge and transforming the self. London, UK: Routledge. doi:10.4324/97802030065

Moss, P. (2010). We cannot continue as we are: The educator in an education for survival. Contemporary Issues in Early Childhood, 11(1), 8-19. doi:10.2304/ciec.2010.11.1.8

Nxumalo, F., Vintimilla, C. D., \& Nelson, N. (2018). Pedagogical gatherings in early childhood education: mapping interferences in emergent curriculum. Curriculum Inquiry, 48(4), 433453. doi:10.1080/03626784.2018.1522930 
Ontario Ministry of Education. (2014a). How does learning happen? Ontario's pedagogy for the early years: A resource about learning through relationships for those who work with young children and their families. Toronto: Author.

Ontario Ministry of Education. (2014b). Excerpts from ELECT: Foundational knowledge from the 2007 publication of "Early learning for every child today: A framework for Ontario early childhood settings". Toronto: Author.

Pacini-Ketchabaw, V., Kummen, K., \& Thompson, D. (2010). Becoming intimate with developmental knowledge: Pedagogical explorations with collective biography. Alberta Journal of Educational Research, 56(3), 335-354.

Pacini-Ketchabaw, V., Taylor, A. \& Blaise, M., (2016). 'De-centring the human in multispecies ethnographies'. In C. Taylor \& C. Hughes (Eds.) Posthuman Research Practices. Hampshire, UK: Palgrave Macmillon.

Rautio, P. (2017). Thinking about life and species lines with Pietari and Otto (and garlic breath). TRACE .: Journal for Human-Animal Studies, 3, 94-102. Retrieved from https://trace.journal.fi/article/view/63310

Spyrou, S. (2018). Disclosing childhoods: Research and knowledge production for a critical childhood studies. London, UK: Palgrave Macmillan.

Taguchi, H. L., Palmer, A., Gustafsson, L. (2016). Individuating 'sparks' and 'flickers' of 'a life' in dance practices with preschoolers: The 'monstrous child' of colebrook's queer vitalism. Discourse: Studies in the Cultural Politics of Education, 37(5), 705-716. doi:10.1080/01596306.2015.1075710

Taylor, A. (2011). Reconceptualizing the 'nature' of childhood. Childhood, 18(4), 420-433. doi:10.1177/0907568211404951 
Taylor, A. (2017). Beyond stewardship: Common world pedagogies for the anthropocene.

Environmental Education Research, 23(10), 1448-1461.

doi:10.1080/13504622.2017.1325452

Taylor, A., \& Pacini-Ketchabaw, V. (2017). Kids, raccoons, and roos: Awkward encounters and mixed affects. Children's Geographies, 15(2), 131-145.

doi:10.1080/14733285.2016.1199849

Vintimilla, C. D. (2018). Encounters with a pedagogista. Contemporary Issues in Early

Childhood, 19(1), 20-30. doi:10.1177/1463949116684886

Wolff, K. (2013). When more is not more: Consumption and consumerism within the neoliberal early childhood assemblage(s). Global Studies of Childhood, 3(3), 328-338.

doi:10.2304/gsch.2013.3.3.328 
References for Article Two

Archer, C., Siraj, I., \& Okely, A. (2017). Movement environment rating scale (MOVERS) for 26-year-olds provision: Improving physical development through movement and physical activity. UCL, UK: IOE Press.

Barad, K. (2007). Meeting the Universe Halfway: Quantum Physics and the Entanglement of Matter and Meaning. Durham, NC: Duke University Pres.

Blaise, M., Hamm, C., \& Iorio, J. M. (2017). Modest witness(ing) and lively stories: Paying attention to matters of concern in early childhood. Pedagogy, Culture \& Society, 25(1), 31-42. doi:10.1080/14681366.2016.1208265

Blaser, M., \& de la Cadena, M. (2017). The uncommons: An introduction. Anthropologica, 59(2), 185-193. doi:10.3138/anth.59.2.t01

Cadena, M. \& Blaser, M. (2018). A world of many worlds. Durham, NC: Duke University Press. Common Worlds Research Collective (2019). About the Collective. Retrieved from http://commonworlds.net/about-the-collective/

Haraway, D. (2016). Staying with the trouble: Making kin in the Cthulucene. Durham, NC: Duke University Press.

Ingold, T. (2011). Being alive: Essays on movement, knowledge and description. London, UK : Routledge. doi:10.4324/9780203818336

Land, N., \& Danis, I. (2016). Movement/ing provocations in early childhood education. Canadian Children, 41(3), 26.

Law J. \& Lien M. (2018). Denaturalizing nature. In Cadena, M. \& Blaser M. (Ed.). A World of Many Worlds (pp.131-171). Durham, UK: Duke University Press. 
Life Media. Mushrooms fight back. (2001, September-October). Natural Life, 20. Retrieved from https://linkgalecom.ezproxy.lib.ryerson.ca/apps/doc/A79747267/CPI?u=rpu_main\&sid=CPI\&xid=7 $258 \mathrm{cf} 9 \mathrm{f}$

Manning, E. (2014). Wondering the world directly - or, how movement outruns the subject. Body \& Society, 20(3-4), 162-188. doi:10.1177/1357034X14546357

Nelson, N., (2019). Rats, death, and Anthropocene relations in urban Canadian childhoods. In Cutter-Mackenzie-Knowles, A., Malone, K., Hacking (Eds.), Research Handbook on Childhoodnature (pp. 1-23). New York, NY: Springer International.

Ontario Ministry of Education. (2014a). Excerpts from ELECT: Foundational knowledge from the 2007 publication of "Early learning for every child today: A framework for Ontario early childhood settings". Toronto: Author.

Ontario Ministry of Education. (2014b). How does learning happen? Ontario's pedagogy for the early years: A resource about learning through relationships for those who work with young children and their families. Toronto: Author.

Pacini-Ketchabaw, V., \& Nxumalo, F. (2015). Unruly raccoons and troubled educators: Nature/Culture divides in a childcare centre. Environmental Humanities, 7(1), 151-168. doi:10.1215/22011919-3616380

Pacini-Ketchabaw, V., \& Kummen, K. (2016). Shifting temporal frames in children's common worlds in the anthropocene. Contemporary Issues in Early Childhood, 17(4), 431-441. doi:10.1177/1463949116677930 
Pacini-Ketchabaw, V., Taylor, A. \& Blaise, M. (2016) 'De-centring the human in multispecies ethnographies'. In C. Taylor \& C. Hughes (Eds.) Posthuman Research Practices in Education, Hampshire, UK: Palgrave Macmillan.

Rautio, P. (2013). Children who carry stones in their pockets: On autotelic material practices in everyday life. Children's Geographies, 11(4), 394-408.

doi:10.1080/14733285.2013.812278

Rautio, P. (2017). Thinking about life and species lines with Pietari and Otto (and garlic breath). TRACE $\therefore$ Journal for Human-Animal Studies, 3, 94-102. Retrieved from https://trace.journal.fi/article/view/63310

Rooney, T. (2019). Weathering time: Walking with young children in a changing climate. Children's Geographies, 17(2), 177-189. doi:10.1080/14733285.2018.1474172

Spyrou, S. (2018). Disclosing childhoods: Research and knowledge production for a critical childhood studies. London, UK: Palgrave Macmillan

St. Pierre, E. A. (2000). Poststructural feminism in education: An overview. International Journal of Qualitative Studies in Education, 13(5), 477-515. doi:10.1080/09518390050156422

Taylor, A. (2013). Reconfiguring the natures of childhood. New York, NY: Routledge.

Taylor, A., \& Pacini-Ketchabaw, V. (2015). Learning with children, ants, and worms in the anthropocene: Towards a common world pedagogy of multispecies vulnerability. Pedagogy, Culture \& Society, 23(4), 507-529. doi:10.1080/14681366.2015.1039050

Taylor, A. (2017). Beyond stewardship: Common world pedagogies for the anthropocene. Environmental Education Research, 23(10), 1448-1461. doi:10.1080/13504622.2017.1325452 
Taylor A., Blaise, M., Hamm, C., \& Iorio, J. M. (2017). Modest witness(ing) and lively stories: Paying attention to matters of concern in early childhood. Pedagogy, Culture \& Society, 25(1), 31-42. doi:10.1080/14681366.2016.1208265

Taylor, A., \& Pacini-Ketchabaw, V. (2017). Kids, raccoons, and roos: Awkward encounters and mixed affects. Children's Geographies, 15(2), 131-145.

doi:10.1080/14733285.2016.1199849

Tsing, A. (2010). Arts of inclusion or, how to love a mushroom. Australian Humanities Review, 50(50). doi:10.22459/AHR.50.2011.01

Tsing, A. L. (2015). The mushroom at the end of the world: On the possibility of life in capitalist ruins. Princeton, US: Princeton University Press.

Vintimilla, C. (2014). Neoliberal fun and happiness in early childhood education. Canadian Children, 39(1), 79.

Vintimilla, C. D. (2018). Encounters with a pedagogista. Contemporary Issues in Early Childhood, 19(1), 20-30. doi:10.1177/1463949116684886

Woods, H., Nelson, N., Yazbeck, S., Danis, I., Elliott, D., Wilson, J,, Pickup, A. (2018). With(in) the forest: (re)conceptualizing pedagogies of care. Journal of Childhood Studies, 43(1), 44-59. doi:10.18357/jcs.v43i1.18264 